\title{
Structural optimisation of vertical-axis wind turbine composite blades based on finite element analysis and genetic algorithm
}

\author{
Lin Wang ${ }^{\mathrm{a}^{*}}$, Athanasios Kolios ${ }^{\mathrm{a}}$, Takafumi Nishino ${ }^{\mathrm{a}}$ \\ Pierre-Luc Delafin ${ }^{\mathrm{a}}$, Theodore Bird ${ }^{\mathrm{b}}$ \\ ${ }^{a}$ Centre for Offshore Renewable Energy Engineering, School of Energy, Environment and Agrifood, \\ Cranfield University, Cranfield, MK43 0AL, UK \\ ${ }^{\mathrm{b}}$ Aerogenerator Project Limited, Ballingdon Mill, Sudbury, CO10 7EZ, UK
}

\begin{abstract}
A wind turbine blade generally has complex structures including several layers of composite materials with shear webs, making its structure design very challenging. In this paper, a structural optimisation model for wind turbine composite blades has been developed based on a parametric FEA (finite element analysis) model and a GA (genetic algorithm) model. The optimisation model minimises the mass of composite blades with multi-criteria constraints. The number of unidirectional plies, the locations of the spar cap and the thicknesses of shear webs are taken as design variables. The optimisation model takes account of five constraints, i.e. stress constraint, deformation constraint, vibration constraint, buckling constraint, and manufacturing manoeuvrability and continuity of laminate layups constraint. The model has been applied to the blade structural optimisation of ELECTRA 30kW wind turbine, which is a novel VAWT (verticalaxis wind turbine) combining sails and V-shape arm. The mass of the optimised blade is $228 \mathrm{~kg}$, which is $17.4 \%$ lower than the initial design, indicating the blade mass can be significantly reduced by using the present optimisation model. It is demonstrated that the structural optimisation model presented in this paper is capable of effectively and accurately determining the optimal structural layups of composite blades.
\end{abstract}

Keywords: Vertical-axis wind turbine; Composite blade; Structural optimisation; Finite element analysis; Genetic algorithm

\begin{tabular}{|ll|}
\hline & \multicolumn{1}{c|}{ Acronyms } \\
APL & Aerogenerator Power Limited \\
CLT & Composite Blade Cross-Section Analysis \\
COE & Classical Lamination Theory \\
\hline
\end{tabular}

${ }^{*}$ Corresponding author. Tel.: +44(0)1234754706; E-mail address: lin.wang@ cranfield.ac.uk 


\begin{tabular}{|ll|}
\hline CTM4E & Cranfield Turbine Model version 4E \\
DECC & Department of Energy \& Climate Change \\
EBSFT & Extended Bredt-Batho Shear Flow Theory \\
FEI & Energy Technologies Institute \\
GA & Finite Element Analysis \\
GL & Genetic Algorithm \\
HAWT & Germanischer Lloyd \\
NAM_WTB & Horizontal-Axis Wind Turbine \\
NOVA & Nonlinear Aeroelastic Model for Wind Turbine Blades \\
PSO & Novel Offshore Vertical Axis \\
SA & Particle Swarm Optimisation \\
VAWT & Simulated Annealing \\
WindPACT & Vertical-Axis Wind Turbine \\
1D & Wind Partnership for Advanced Component Technologies \\
3D & One-Dimensional \\
\hline
\end{tabular}

\begin{tabular}{|ll|}
\hline$d_{\max }$ & \multicolumn{1}{c|}{ Nomenclature } \\
$d_{\text {allow }}$ & Maximum blade deformation \\
$E_{x}$ & Allowable deformation \\
$E_{y}$ & Longitudinal Young's modulus \\
$f_{\text {blade }}$ & Lateral Young's modulus \\
$f_{\text {rotor }}$ & First natural frequency of the blade \\
$f_{s}$ & Frequency of the rotor rotation \\
$F_{\text {obj }}$ & Material safety factor \\
$G_{x y}$ & Objective function \\
$L_{m}$ & Shear modulus \\
$L_{m_{-} \text {allow }}$ & Load multiplier \\
$m_{B}$ & Allowable load multiplier \\
$N_{\text {Ini }}$ & Mass of the blade \\
$N_{\text {MaxEval }}$ & Number of initial samples \\
$N_{\text {Maxiter }}$ & Maximum number of evaluations \\
$N_{\text {Perlter }}$ & Maximum number of iterations \\
\hline & Number of samples per iteration \\
\hline
\end{tabular}




\begin{tabular}{|ll|}
\hline$t_{p l y}$ & Ply thickness \\
$x_{1}, x_{2}, \cdots, x_{n}$ & Design variables \\
$x^{L}$ & Lower bound of design variables \\
$x^{U}$ & Upper bound of design variables \\
$X$ & Row matrix that contains all design variables \\
$v_{x y}$ & Poisson's ratio \\
$\rho$ & Material density \\
$\sigma_{C, \text { allow }}$ & Allowable longitudinal compressive stress \\
$\sigma_{C, \text { max }}$ & Maximum longitudinal compressive stress \\
$\sigma_{C, \text { ulti }}$ & Ultimate longitudinal compressive stress \\
$\sigma_{T, \text { allow }}$ & Allowable longitudinal tensile stress \\
$\sigma_{T, \text { max }}$ & Maximum longitudinal tensile stress \\
$\sigma_{T, \text { ulti }}$ & Ultimate longitudinal tensile stress \\
$\Delta_{\text {allow }}$ & Allowable tolerance \\
\hline
\end{tabular}

\section{Introduction}

Deployment of offshore wind farms during the past decade has highlighted some difficulties associated with conventional wind turbines. Conventional HAWTs (horizontal-axis wind turbines) place their main components (such as the rotor and drive-train) at the top of very tall towers, making both installation and maintenance difficult and limiting their size. VAWTs (vertical-axis wind turbines) can overcome the above disadvantages by locating their main components at the base of the wind turbine, offering easy access for both installation and maintenance. Additionally, VAWTs are insensitive to wind direction and therefore there is no need for sophisticated yawing system, which significantly reduces the cost of the turbine. Therefore, there has been a resurgence of interest in the development of VAWTs for offshore applications [1-3].

The conventional VAWTs based on the Darrieus concept [4] encounter a large aerodynamic overturning moment, which results in very heavy drive-train components. In order to minimise the aerodynamic overturning moment, Sharpe [5] proposed a novel V-shape VAWT rotor, which combines a V-arm with several sails positioned along the span. Fig. 1 presents a photograph of a $5 \mathrm{~kW}$ prototype device developed by Wind Power Ltd based on the novel V-shape rotor. 


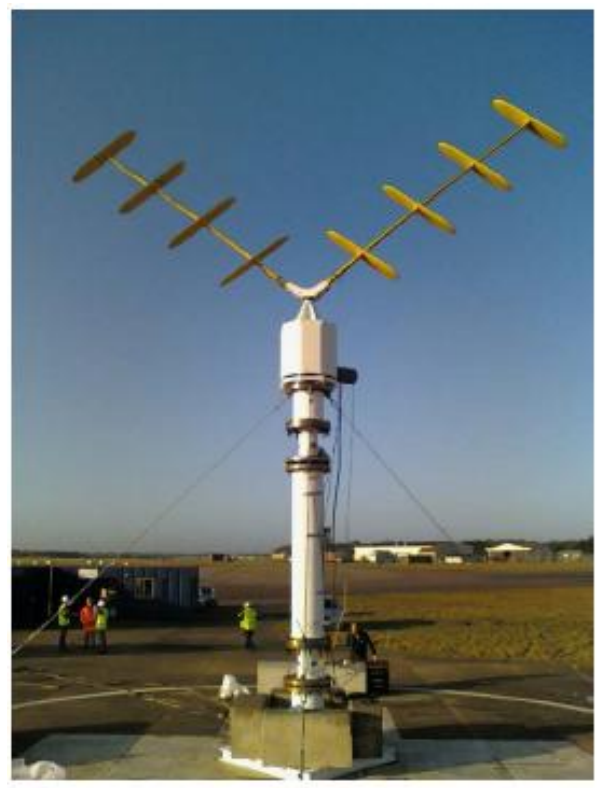

Figure 1. 5kW prototype device developed by Wind Power Ltd [6]

In 2009, ETI (Energy Technologies Institute) commissioned NOVA (Novel Offshore Vertical Axis) project [7], which is a $£ 2.8 \mathrm{M}$ feasibility study project to develop the concept design of a novel 10MW offshore VAWT based on the novel V-shape rotor. Through case studies, it is demonstrated that using two highaspect-ratio (i.e. large span-to-chord ratio) sails is more aerodynamically efficient than multiple lowaspect-ratio sails. This is due to the fact that the two-sail design experiences lower junction flows, which result in lower interference drags. Therefore a new V-shape with two-sail concept design is proposed in the NOVA project, as illustrated in Fig. 2.

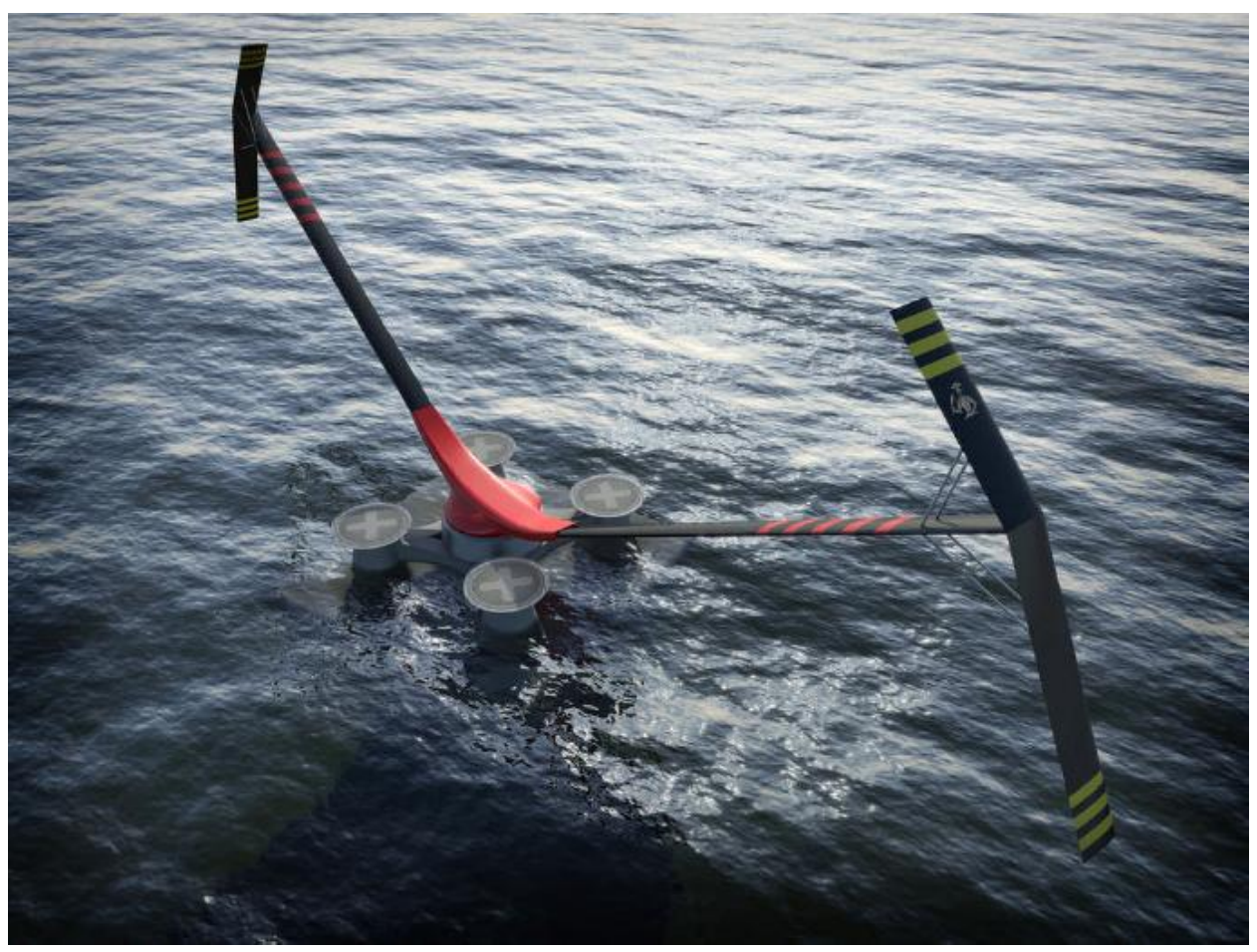

Figure 2. Concept design of NOVA 10MW wind turbine [7] 
Based on the V-shape and two-sail concept, the ELECTRA 30kW vertical-axis wind turbine is currently being developed in the $30 \mathrm{~kW}$ Aerogenerator project, which is an on-going project (commenced in January 2015) and is funded by both DECC (Department of Energy \& Climate Change) and APL (Aerogenerator Power Limited). The ELECTRA $30 \mathrm{~kW}$ turbine will be built and tested, and it will also be used to demonstrate and generate information to scale up for offshore application.

Blades are key components of a wind turbine. The aerodynamic shape of a wind turbine blade is generally optimised in order to achieve better power performance [8-10]. In terms of the structure, wind turbine blades are generally made of composite materials due to their high strength-to-weight ratio and good fatigue performance. In order to meet design requirements, wind turbine blades commonly have complex structural layout, comprising one or more shear webs and a number of composite plies placed at different ply angles $[11,12]$. The structural performance of a composite blade can be tailored by changing stacking sequence, fibre orientation, stacking location and size of the materials. Due to the inherent complexity of composite materials and the complicated blade structural layout, optimisation of a composite blade is very challenging and requires a specialised structural optimisation model.

In general, a structural optimisation model of wind turbine composite blades consists of two components, i.e. 1) a blade structural model, which determines the structural performance of the blade, such as blade mass and stress distributions; and 2) an optimisation algorithm, which handles the design variables and searches for the optimal solutions.

Structural models used for wind turbine blades can be roughly categorised into two groups, i.e. 1D (onedimensional) beam model and 3D (three-dimensional) FEA (finite element analysis) model. Due to its efficiency and reasonable accuracy, beam model has been widely used in aeroelasticity analysis and structural dynamics analysis of wind turbine blades. Based on a nonlinear beam model, Wang et al. [13] developed a nonlinear aeroelastic model called NAM_WTB (Nonlinear Aeroelastic Model for Wind Turbine Blades), which takes account of geometric nonlinearities and large blade deformations. The main input data of the beam model are the cross-sectional properties, such as mass per unit length and crosssectional stiffness, which can be calculated by using specialised cross-sectional analysis models. An example of such cross-sectional analysis models is CBCSA (Composite Blade Cross-Sectional Analysis) [14], which is developed by Wang et al. through combining CLT (Classical Lamination Theory) [15] and EBSFT (Extended Bredt-Batho Shear Flow Theory) [16]. Although it is efficient, the beam model is incapable of offering some important information for the blade design, such as detailed stress distributions within each layer of the blade structure. In order to obtain such detailed information, it is necessary to construct the blade structure model using 3D FEA. In 3D FEA, wind turbine composite blades are generally constructed using 3D composite shell elements, which are capable of describing composite layer characteristics throughout the shell thickness. Compared to the 1D beam model, the 3D FEA model 
provides more accurate results and is able to predict detailed stress distributions within the blade structure. For this reason, the 3D FEA model is chosen in this study to model the composite blade structure.

Optimisation algorithms used for wind turbine blades can be roughly categorised into three groups [17], i.e. exact algorithms, heuristic algorithms and metaheuristic algorithms. Exact algorithms evaluate every possible combination of design variables to find the best solution. It is a very accurate approach because all possible combinations are evaluated. However, it becomes inefficient and even infeasible in cases of a large number of design variables, requiring huge computational costs to evaluate all possible combinations. Heuristic algorithms (also known as approximate algorithms) find near-optimal solutions based on semiempirical rules. Heuristic algorithms are more efficient than exact algorithms, but they are problemdependent and their accuracy depends on the accuracy of semi-empirical rules, limiting their applications to some extent. Metaheuristic algorithms (also known as hyper-heuristics), which are more complex and intelligent heuristics, are high-level problem-independent algorithms to find near-optimal solutions. Metaheuristic algorithms are more efficient than common heuristic and are generally based on optimisation processes observed in the nature, such as SA (simulated annealing), PSO (particle swarm optimisation) and GA (genetic algorithm). Among these metaheuristic algorithms, the GA, which finds solutions to optimisation problems using techniques inspired by genetics and natural evolution, has the ability to handle a large number of design variables and to avoid being trapped in local optimal solution, making it the most widely used metheuristic algorithm for the optimisation of wind turbine blades [18, 19]. For this reason, the GA is chosen in this study to handle the design variables and to search for the optimal solutions.

To the best of the authors' knowledge, the combination of FEA and GA for structural optimisation of vertical-axis wind turbine blades has not been reported in the literature. This paper attempts to combine FEA and GA to develop a structural optimisation model of wind turbine composite blades. A parametric FEA model is developed, and then it is coupled with GA to develop a structural optimisation model. The structural optimisation model is applied to the ELECTRA $30 \mathrm{~kW}$ wind turbine blade, which is a novel VAWT blade, to optimise the structural layout of the blade.

This paper is structured as follows. Section 2 illustrates the ELECTRA 30kW wind turbine blade. Section 3 presents the parametric FEA model of wind turbine composite blades. Section 4 presents the GA model. Section 5 presents the optimisation model by combining the parametric FEA model and the GA model. Results and discussions are provided in Section 6, followed by conclusions in Section 7.

\section{ELECTRA 30kW Wind Turbine Blade}

The wind turbine model used in the present study is the ELECTRA 30kW wind turbine, which is a novel 2bladed VAWT combining V-shape and sails. The two blades of the turbine are designed to be identical, and therefore only a single blade is needed in this study. The aerodynamic shape of the blade is being 
optimised by the $30 \mathrm{~kW}$ Aerogenerator project team. In this study, a preliminary aerodynamic design of the ELECTRA 30kW wind turbine blade is used, and its schematic is presented in Fig. 3.

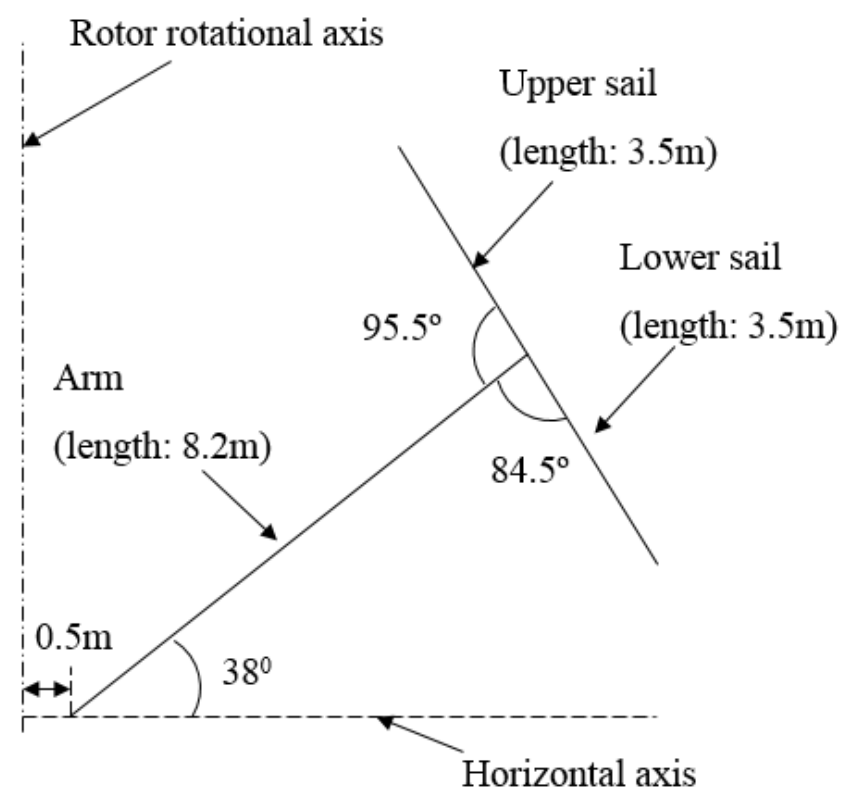

Figure 3. Schematic of preliminary aerodynamic design of ELECTRA 30kW wind turbine blade

As can be seen from Fig. 3, the blade consists of three parts, i.e. arm, upper sail and lower sail. The length of the arm is $8.2 \mathrm{~m}$, and the angle between the arm and the horizontal axis is $38^{\circ}$. The length of the upper sail is $3.5 \mathrm{~m}$, and the angle between the upper sail and the arm is $95.5^{\circ}$. The length of the lower sail is $3.5 \mathrm{~m}$, and the angle between the lower sail and the arm is $84.5^{\circ}$. The arm root offsets $0.5 \mathrm{~m}$ from the rotor rotational axis.

The preliminary aerodynamic design of the ELECTRA 30kW blade comprises two different airfoil shapes, i.e. NACA0040 and NACA0018, as shown in Table 1.

Table 1. Preliminary aerodynamic design of ELECTRA 30kW blade

\begin{tabular}{lll}
\hline & Chord $(\mathrm{m})$ & Profile \\
\hline Arm & 0.6 & NACA0040 \\
Upper sail & 0.8 & NACA0018 \\
Lower sail & 0.8 & NACA0018 \\
\hline
\end{tabular}

\section{Parametric FEA model}

\subsection{Model description}

A parametric FEA model of wind turbine composite blades is established using ANSYS software [20]. It is a parametric model, which means that the structural parameters of composite blades can be easily modified 
to create various blade models. The parametric FEA model can be applied to the FEA modelling of both horizontal-axis and vertical-axis wind turbine composite blades, and its flowchart is presented in Fig. 4.

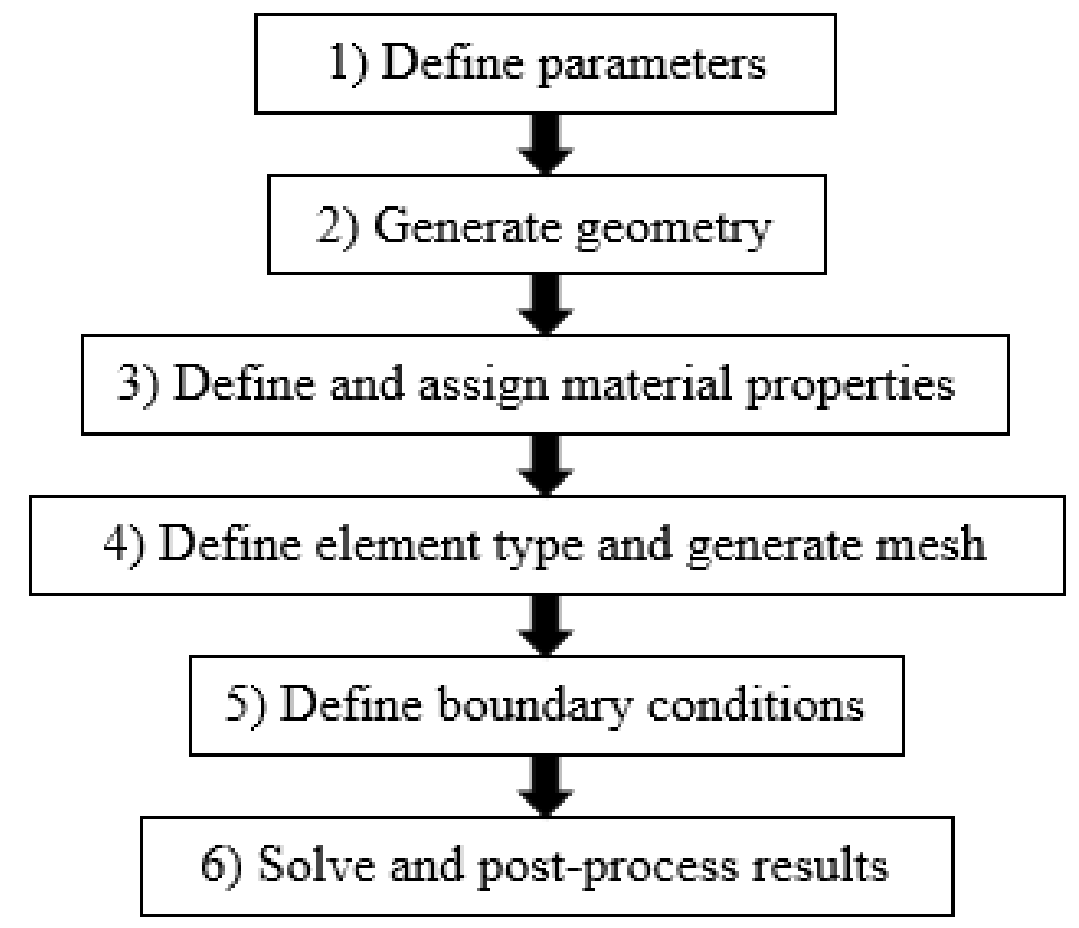

Figure 4. Flowchart of the parametric FEA model.

Each step of the flowchart in Fig. 4 is detailed below.

1) Define parameters

In the first step, parameters involved in the FEA modelling, such as structure thickness and geometry data, are defined.

2) Generate geometry

The blade geometry is generated based on the bottom-up approach, which generates low dimensional entities (such as points) and build on top of them higher dimensional entities (such as lines and areas).

3) Define and assign material properties

In this step, material properties are defined and then assigned to the blade structure.

4) Define element type and generate mesh

In term of element type, the shell element shell281, which has eight nodes with six degrees of freedom at each node, is used. The Shell281 element is well-suited for linear, large rotation, and/or large strain nonlinear applications. It is also suitable for layered applications for modelling composite shells or sandwich structure. Details of the Shell281 element can be found in ANSYS help documentation [21]. 
Additionally, a regular quadrilateral mesh generation method is utilised to create high quality elements.

5) Define boundary conditions

In this step, boundary conditions is applied. The types of boundary conditions depend on the types of analysis. For example, for modal analysis, a fixed boundary condition is applied at the blade root.

6) Solve and post-process results

Having defined parameters, geometry, material, mesh, element properties and boundary conditions, different types of analysis, such as static analysis, modal analysis and time-dependent analysis, can be performed. The analysis results, such as deformations and stress distributions, are then plot using postprocessing functions of ANSYS software.

\subsection{Validation of the parametric FEA model}

A case study is performed in order to validate the parametric FEA model. The WindPACT 1.5MW wind turbine [22-24], which is a representative of large-scale HAWTs, is chosen as an example. The reasons of choosing a HAWT blade in the validation study are 1) HAWT blades have similar structures with VAWT blades (for instance, both of them use airfoil cross sections made of composite materials); and 2) no data of VAWT blades are publicly available for validation case studies.

WindPACT $1.5 \mathrm{MW}$ wind turbine is a reference wind turbine designed by NREL (National Renewable Energy Laboratory) for the WindPACT (Wind Partnership for Advanced Component Technologies) project between years 2000 and 2002. In the WindPACT project, the effects of the main wind turbine components (such as blades and generator) on the cost of energy (COE) have been investigated. The ultimate goal of the WindPACT project is to identify technology improvements to reduce the COE of wind turbines in low-wind-speed sites. Details of the WindPACT project can be found in Ref. [25]. WindPACT $1.5 \mathrm{MW}$ wind turbine is a three-bladed HAWT, and its main parameters are summarised in Table 2. The material properties and detailed structural layups of the WindPACT wind turbine blade can be found in Ref. [24].

Table 2. Main parameters of the WindPACT 1.5MW wind turbine

\begin{tabular}{ll}
\hline Parameters & Values \\
\hline Rated power (MW) & 1.5 \\
Number of blades & 3 \\
Rotor radius $(\mathrm{m})$ & 35 \\
\hline
\end{tabular}

The parametric FEA model presented in Section 3.1 is applied to the FEA modelling of the WindPACT $1.5 \mathrm{MW}$ wind turbine blade. A regular quadrilateral mesh generation method is utilised to create high 
quality elements. The created mesh is depicted in Fig. 5, and a close view of the blade tip is presented in Fig. 6.

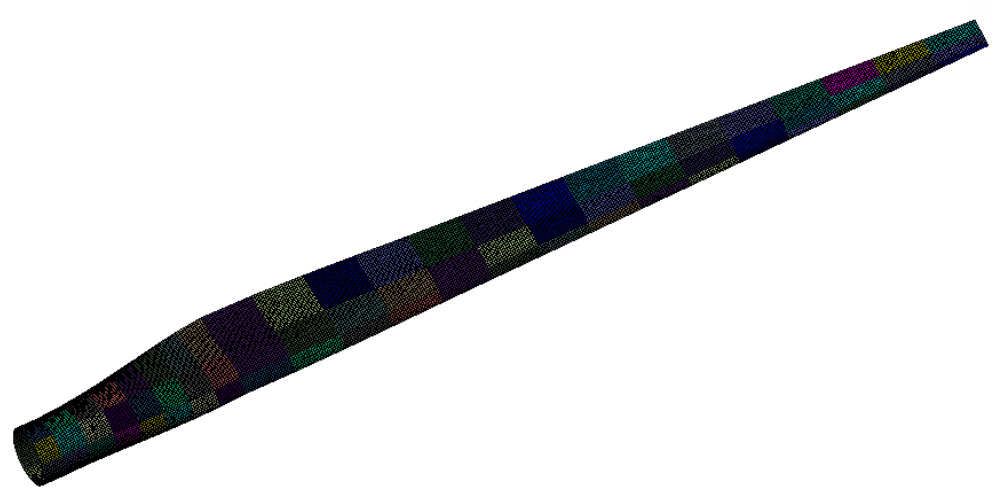

Figure 5. Mesh of WindPACT 1.5MW wind turbine blade

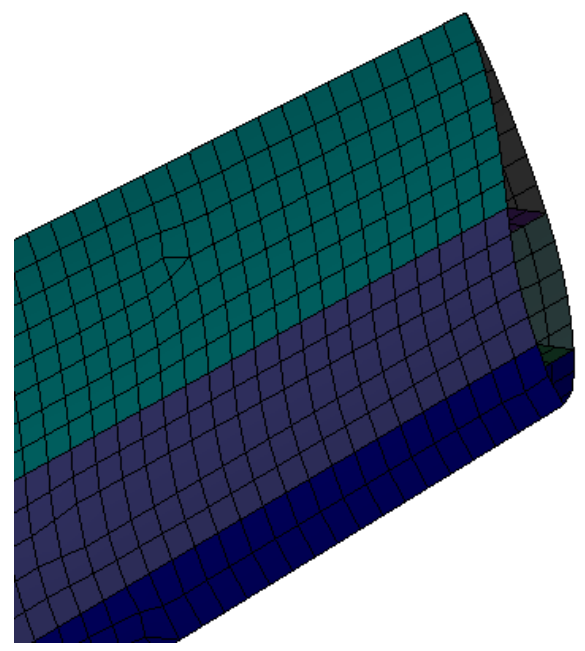

Figure 6. Close view of blade tip

The FEA model is used to perform modal analysis of the WindPACT $1.5 \mathrm{MW}$ wind turbine blade. In this case study, the blade is non-rotating and free-vibration (no loads on the blade). A fixed boundary condition is applied to the blade root. The results of the proposed FEA model are compared against the FEA results reported in Ref. [24], as shown in Fig. 7 and Table 3. 


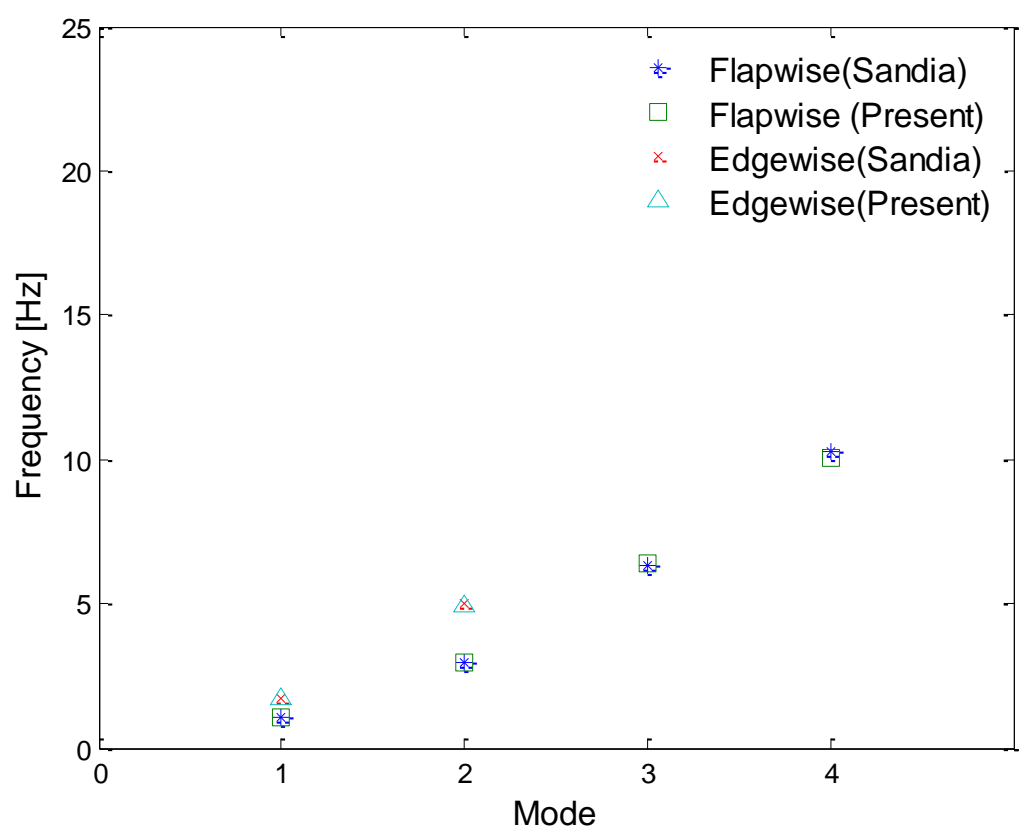

Figure 7. Mode frequencies of WindPACT 1.5MW wind turbine blade

Table 3. Mode frequencies of WindPACT 1.5MW wind turbine blade

\begin{tabular}{llll}
\hline Mode frequencies & Reference [24] & Present & \%Diff \\
\hline $1^{\text {st }}$ flapwise $(\mathrm{Hz})$ & 1.0783 & 1.0508 & 2.55 \\
$1^{\text {st }}$ edgewise $(\mathrm{Hz})$ & 1.7001 & 1.7003 & 0.01 \\
$2^{\text {nd }}$ flapwise $(\mathrm{Hz})$ & 2.9804 & 2.9329 & 1.59 \\
$2^{\text {nd }}$ edgewise $(\mathrm{Hz})$ & 5.0382 & 4.9672 & 1.41 \\
$3^{\text {rd }}$ flapwise $(\mathrm{Hz})$ & 6.3093 & 6.3978 & 1.40 \\
$4^{\text {th }}$ flapwise $(\mathrm{Hz})$ & 10.305 & 10.034 & 2.63 \\
\hline
\end{tabular}

As can be seen from Fig. 7 and Table 3, the flapwise and edgewise blade mode frequencies calculated from the present FEA model show good agreement with the FEA results reported in Ref. [24], with the maximum percentage difference $(2.63 \%)$ occurring for the $4^{\text {th }}$ edgewise mode. This confirms the validity of the present parametric FEA model.

\subsection{Application of the parametric FEA model to the ELECTRA 30kW wind turbine blade}

The parametric FEA model is applied to the FEA modelling of the ELECTRA 30kW wind turbine blade. The geometry, material properties, layout of the airfoil cross section, mesh, boundary conditions used in the FEA modelling are presented below. 


\subsubsection{Geometry}

Based on the aerodynamic shape presented in Section 2, the 3D geometry of the ELECTRA 30kW wind turbine blade is created, as depicted in Fig. 8. The circular arm root and arm tip are connected to the hub and rectangular sail root using T-bolts, respectively. In this case study, for the sake of simplicity, the T-bolts and associated holes are not considered in the FEA modelling.

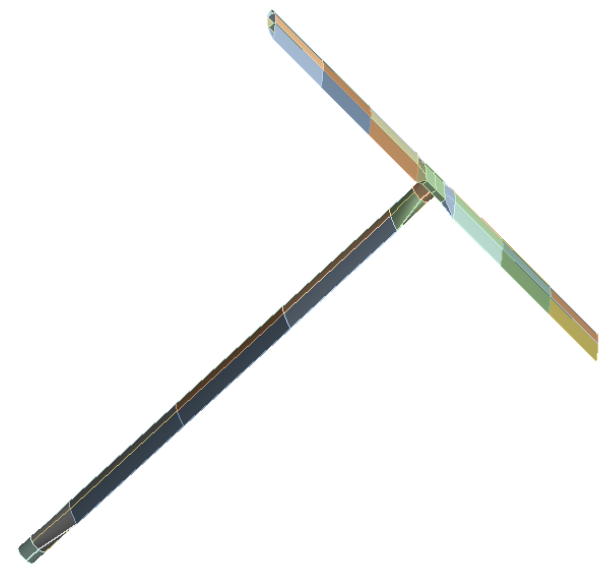

Figure 8. Geometry of the ELECTRA 30kW wind turbine blade

\subsubsection{Material properties}

The blade structure is designed to be made of five types of materials, i.e. gelcoat, random mat, DBM1708 (double-bias E-glass fibre), C260 (unidreictional E-glass fibre) and End-grain Balsa. The mechanical properties of these materials are presented in Table 4 . It should be noted that the materials for this study are obtained from Refs. [26, 27] rather than manufacturing datasheets, as the real fabrication data are proprietary material and very challenging to obtain.

Table 4. Mechanical properties of materials [26, 27]

\begin{tabular}{lllllll}
\hline Material name & $E_{x}(\mathrm{GPa})$ & $E_{y}(\mathrm{GPa})$ & $G_{x y}(\mathrm{GPa})$ & $v_{x y}$ & $\rho\left(\mathrm{kg} / \mathrm{m}^{3}\right)$ & $t_{p l y}(\mathrm{~mm})$ \\
\hline Gelcoat & 3.44 & 3.44 & 1.38 & 0.3 & 1235 & 0.38 \\
Random mat & 7.58 & 7.58 & 4.00 & 0.30 & 1678 & 0.38 \\
DBM1708 & 9.58 & 9.58 & 6.89 & 0.39 & 1814 & 0.89 \\
C260 & 42.32 & 9.72 & 6.48 & 0.3 & 1737 & 0.6 \\
End-grain balsa & 0.12 & 0.12 & 0.02 & 0.3 & 230 & -
\end{tabular}

(where $E_{x}$ is the longitudinal Young's modulus; $E_{y}$ is the lateral Young's modulus; $G_{x y}$ is the shear modulus; $v_{x y}$ is the Poisson's ratio; $\rho$ is the density; $t_{p l y}$ is the thickness of the ply) 


\subsubsection{Layout of the airfoil cross section}

The airfoil cross section of the composite blade is presented in Fig. 9. As can be seen from Fig. 9, the blade cross section is a three-cell section with two shear webs. The outermost skin of the cross section consists of three layers, i.e. a gelcoat layer, a nexus layer and a double-bias-material composite laminate. The gelcoat outer layer offers a smooth surface. Even though it is not a structural material, it can considerably contribute to the blade mass. The nexus is a soft-material mat, protecting the rough surface of the underlying double-bias laminate and providing an absorbent surface for the gelcoat. Double-bias layers are mainly to provide shear strength and to avoid splaying of the unidirectional material. At both leading- and trailing-edge panels, the double-bias laminate splits into two layers to accommodate a core material (e.g. balsa), which augments the buckling strength of the blade.

A composite box-spar is enclosed in the midsection of the blade and is connected to the skin double-bias layers at its lower and upper surfaces. The box-spar splits the cross section into three cells, with the boxspar forming the mid-cell. The spar cap is mainly made of unidirectional composite laminates, which provide most of the bending strength due to their good axial load-bearing capabilities. The two vertical sides of the box-spar serve as shear webs, consisting of double-bias composite laminate and core material.

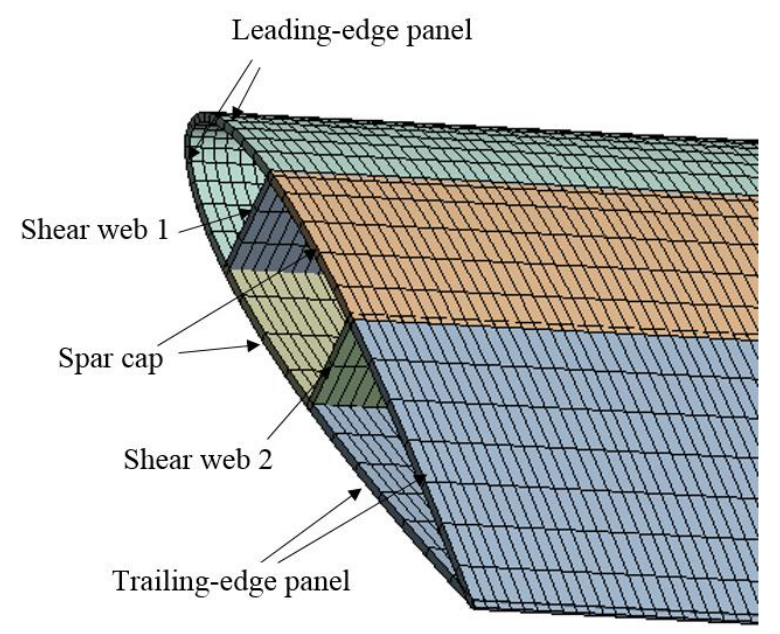

Figure 9. Layout of airfoil cross section

\subsubsection{Mesh}

The mesh of the blade is presented in Fig. 10, and a close view of the sail tip is presented in Fig. 11. The blade structure is meshed using structured mesh with shell elements. 


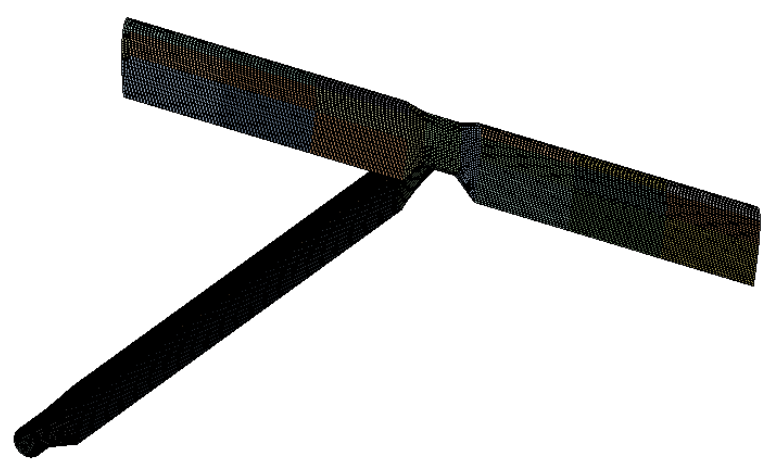

Figure 10. Mesh of the ELECTRA 30kW wind turbine blade

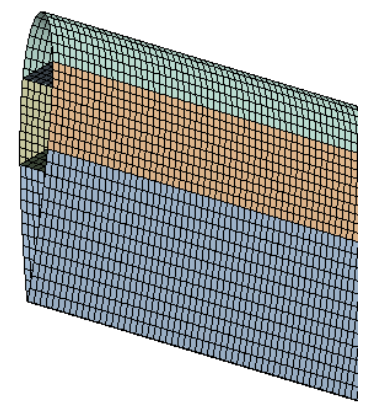

Figure 11. Close view of the sail tip

\subsubsection{Boundary conditions}

The main loads on a wind turbine blade are the aerodynamic loads exerted by the airflow passing the blades. The aerodynamic loads used in this study are calculated using an in-house aerodynamic code called CTM4E (Cranfield Turbine Model version 4E), which is developed by Shires [28] in the NOVA project. The CTM4E code is based on Paraschivoiu's DMST (Double-Multiple Streamtube) model [29], which performs separate calculations of the induced velocity over upwind and downwind half-cycles of the rotor. CTM4E code takes account of three-dimensional considerations for tip losses, tower losses and junction drag. The CTM4E code has been validated by extensive benchmark tests [28], showing reasonable agreement with experimental data.

The aerodynamic loads are calculated by CTM4E code under a 50-year extreme wind condition (wind speed is $52.5 \mathrm{~m} / \mathrm{s}$ ) with a parked rotor (i.e. rotor rotational speed is $0 \mathrm{rpm}$ ). The overall aerodynamic overturning moment on the blade root is $44.9 \mathrm{kNm}$, taking account of a load safety factor of 1.35 according to design standard IEC61400-2 [30]. The calculated aerodynamic loads are applied to the pressure-side of the blade surface as distributed loads.

In addition to aerodynamic loads, the gravity loads are considered in this study. Additionally, a fixed boundary condition is applied to the arm root. 
The boundary conditions used in the FEA modelling are presented in Fig. 12.

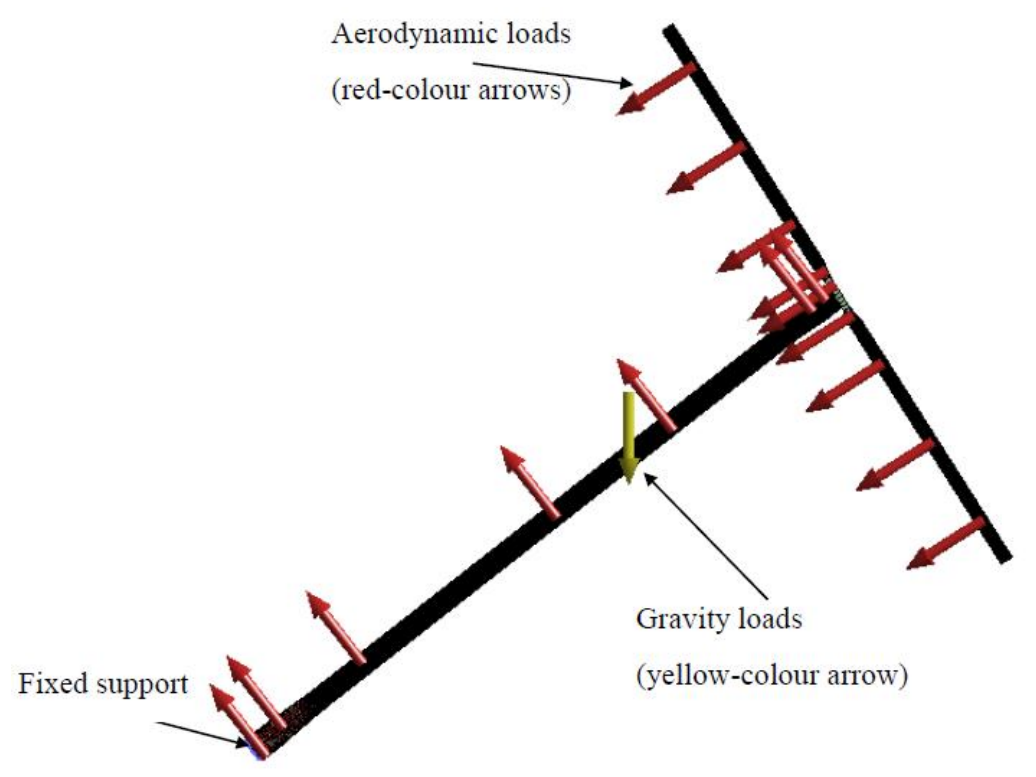

Figure 12. Boundary conditions

\section{Generic algorithm (GA)}

A GA (genetic algorithm) [31] is chosen for finding the optimum solution. The GA imitates the fundamental principles of genetics and natural selection to constitute its optimisation procedures. In the GA, a population of individuals (i.e. candidate solutions) to an optimisation problem is evolved gradually toward better solutions. The evolution usually starts with an initial population, of which individuals are created randomly. It is an iterative process, and the population in each iteration is called a generation. In each generation, the fitness of each individual in the population is evaluated, and the fitness is usually the value of the objective function of the optimisation problem. The individuals with high fitness values are stochastically chosen from the present population. The genome of each individual is modified to form a new generation through two ways, i.e. 1) mutation, which alters one or more gene values in a chromosome from its initial state to form entirely new gene values being added to the gene pool; and 2) crossover, which combines two chromosomes to produce a new chromosome. The new generation of individuals is then used in the next iteration of the evolution. The evolution generally terminates when either the population has reached a satisfactory fitness level, or a maximum number of generations has been produced. The mutation and crossover used in the GA are briefly summarised below.

\section{- Mutation}

Mutation operator is analogous to biological mutation, and it alters one or more gene values in a chromosome from their initial state. Mutation can contribute to entirely new gene values being added to the gene pool, possibly resulting in a better solution. Mutation plays a significant role in the genetic search, as it helps to preserve and introduce diversity, preventing the population from stagnating at any local 
optima. A specified mutation probability is generally used to control the occurrence of mutation during evolution. This probability should not be too high. Otherwise, the genetic search will become a basic random search.

\section{- Crossover}

Crossover plays an important role in generating a new generation. Crossover mates (combines) two chromosomes (parents) to generate a new chromosome (offspring). The basic idea behind crossover is that the new chromosome might be better than both of the parents in cases that it takes the best characteristics from each parent.

GA searches optimal solutions through an iterative procedure, which is presented below.

1) Define objectives, variables and constraints

The first step of GA is to define optimisation objectives, design variables and constraints.

2) Initialise population

In this step, GA randomly generates the initial population (samples). Large initial population set increases the chance to find the input design variable space that contains the best solutions.

3) Generate a new population

In this step, GA generates a new population through mutation and crossover.

4) Design point update

In this step, the design points in the new population are updated.

\section{5) Convergence validation}

The optimisation converges when the convergence criteria have been reached. If the optimisation is not converged, the evolution process continues to the next step.

\section{6) Stopping criteria validation}

If the optimisation has not yet converged, it is then further validated for fulfilment of stopping criterion, i.e. the maximum number of iterations criterion. If the iteration number exceeds the maximum number of iterations, the optimisation process is stopped without having reached convergence. Otherwise, the optimisation process returns to Step 3 to generate a new population.

The above Steps 3 to 6 are repeated in sequence until the optimisation has converged or the stopping criterion has been met. The flowchart of GA is presented in Fig. 13. 


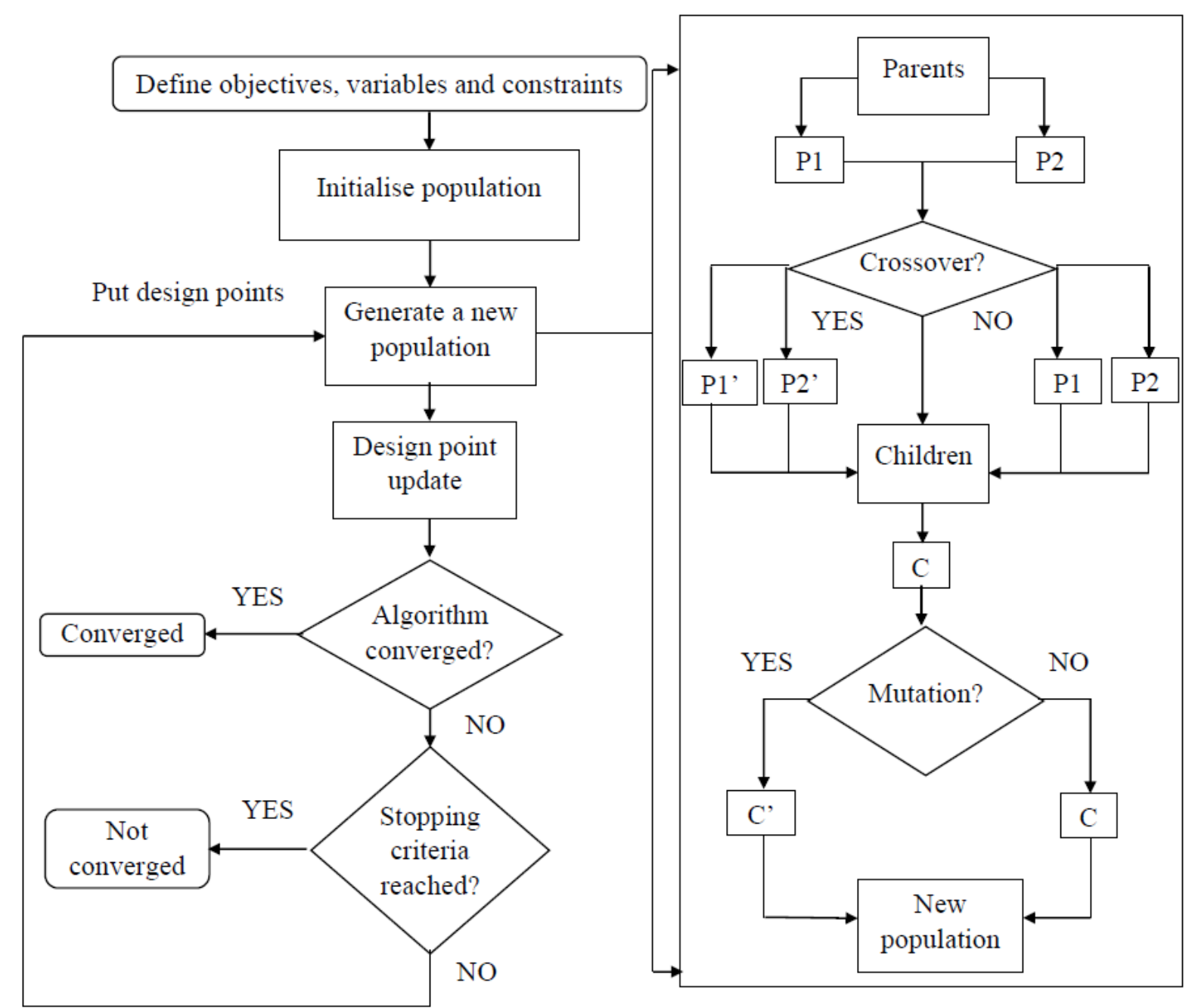

Figure 13. Flowchart of genetic algorithm

\section{Structural optimisation model of composite blades}

\subsection{Objective function}

In order to reduce the material cost of the wind turbine blade, the blade structure is required to be designed as light as possible. Moreover, the lighter blade mass can also be beneficial to reduce both centrifugal and gravity loads on the blade. Therefore, the minimum blade mass is taken as the objective function, expressed as:

$$
F_{o b j}=\min \left(m_{B}\right)
$$

where $F_{o b j}$ and $m_{B}$ are the objective function and blade mass, respectively. 


\subsection{Design variables}

Figure 14 presents the schematic of the blade structure. As can be seen from Fig. 14, the blade structure is divided into 16 regions, including 7 regions on the arm and 9 regions on the sail. ArmRoot and ArmRootTran are arm-root region and arm-root transition region, respectively. ArmAF1, ArmAF2 and ArmAF3 are arm airfoil regions. ArmTipTran and ArmTip are arm-tip transition region and arm-tip region, respectively. SailRoot, SailUpTran and SailDownTran are sail-root region, upper-sail transition region and lower-sail transition region, respectively. SailUpAF1, SailUpAF2 and SailUpAF3 are upper-sail airfoil regions. SailDownAF1, SailDownAF2 and SailDownAF3 are lower-sail airfoil regions. The materials used in the structural design (i.e. gelcoat, random mat, double-bias plies, unidirectional plies and balsa) are presented in Section 3.3.2.

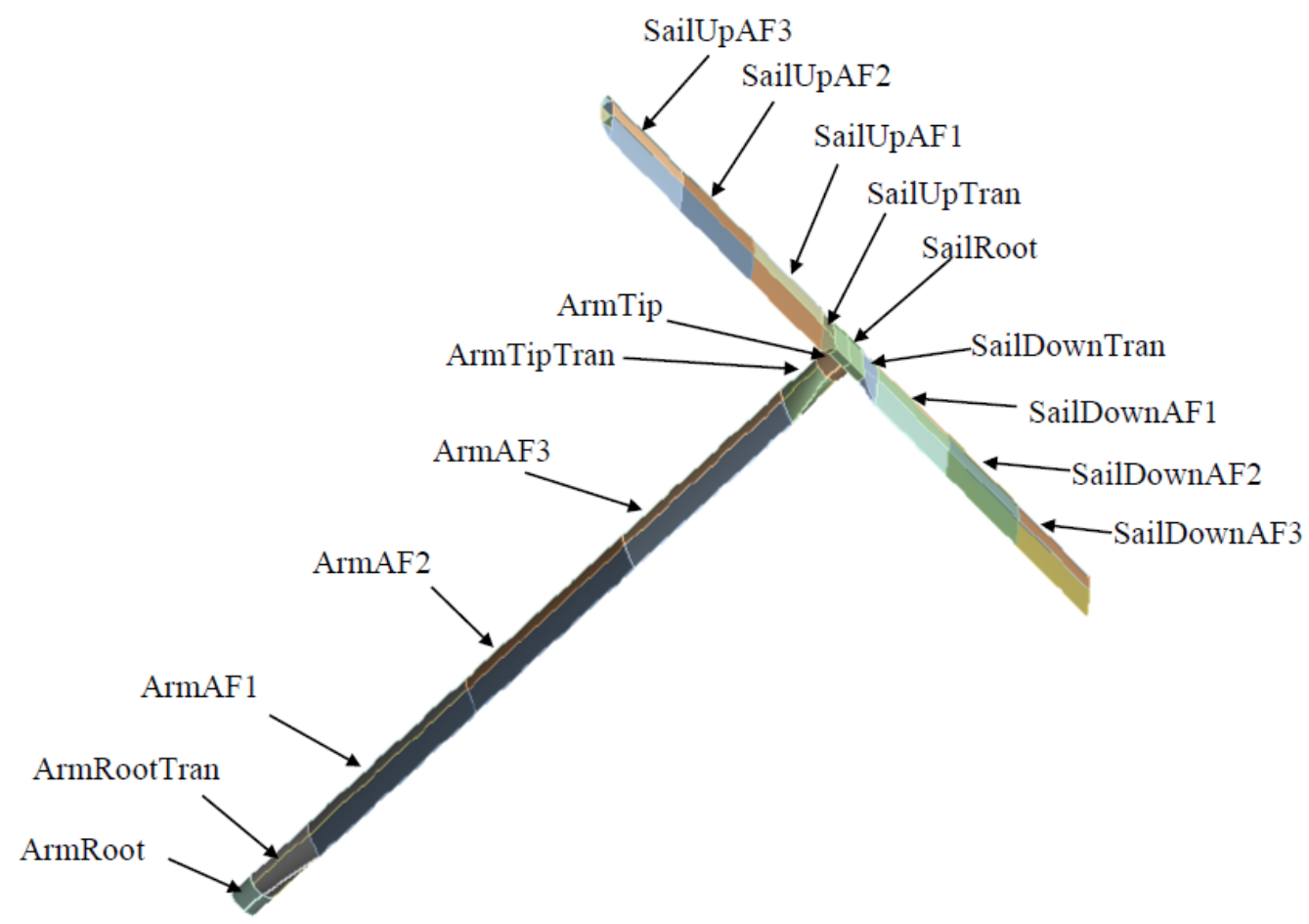

Figure 14. Schematic of the blade structure

Compared to unidirectional plies, the double-bias plies usually offers a much lower stiffness along the blade. The main role of the double-bias plies is to prevent splaying of the unidirectional plies and to provide shear strength. The shear-strength criteria might not yield any requirement for double-bias plies, as wind turbine blades are generally subjected to low torsion loads. Therefore, an empirical value of 2 is chosen as the number of double-bias plies. A single layer is used for the non-structure materials, i.e. gelcoat and random mat. Table 5 presents the number of layers of gelcoat, random mat and double-bias plies used in the blade structural design. The thickness of a single layer in Table 5 is the ply thickness $t_{p l y}$ given in Table 4 (see Section 3.3.2). 
Table 5. Number of layers of double-bias plies, gelcoat and random mat

\begin{tabular}{lll}
\hline Item & Number of layers & Thickness of a single layer $[\mathrm{mm}]$ \\
\hline Gelcoat & 1 & 0.38 \\
Random mat & 1 & 0.38 \\
Bouble-bias E-glass & 2 & 0.6 \\
\hline
\end{tabular}

The unidirectional plies carry most of the bending loads, and they generally contribute most of the overall weight of the blade. In addition, the location of the spar cap and the thickness of the shear webs can also significantly affect the weight of the blade. Therefore, the number of unidirectional plies, the location of the spar cap and the thickness of shear webs are taken as design variables. The thickness of the core material (i.e. balsa) at both airfoil leading- and trailing-edge panels is designed be identical to the thickness of the unidirectional plies in the spar cap, in order to have a smooth transition between the panel and the spar cap to avoid local stress concentration.

Thus, twenty-three design variables in total are defined, which can be expressed in the following form:

$$
X=\left[\begin{array}{llll}
x_{1} & x_{2} & \cdots & x_{n}
\end{array}\right]^{T}, \quad n=23
$$

where $x_{1}$ is the number of unidirectional plies of the arm-root region; $x_{2}$ is the number of unidirectional plies of the arm-root transition region; $x_{3}, x_{4}$ and $x_{5}$ are the number of unidirectional plies in the spar cap of the arm airfoil regions; $x_{6}$ is the number of unidirectional plies of the arm-tip transition region; $x_{7}$ is the number of unidirectional plies of the arm-tip region; $x_{8}$ is the number of unidirectional plies of the sail-root region; $x_{9}$ is the number of unidirectional plies of the upper-sail transition region; $x_{10}, x_{11}$ and $x_{12}$ are the number of unidirectional plies of the upper-sail airfoil regions; $x_{13}$ is the number of unidirectional plies of the lower-sail transition region; $x_{14}, x_{15}$ and $x_{16}$ are the number of unidirectional plies of the lower-sail airfoil regions; $x_{17}, x_{18}$ and $x_{19}$ are the thickness of shear webs of the arm, upper sail and lower sail, respectively; $x_{20}$ and $x_{21}$ are the normalized chordwise locations of spar cap of the arm; $x_{22}$ and $x_{23}$ are the normalized chordwise locations of spar cap of both upper sail and lower sail.

\subsection{Constraints}

The structural optimisation of wind turbine composite blades requires multiple criteria to be taken into account. In many cases, these criteria are mutually incomparable and sometimes even contradictory. In this paper, five constraint conditions are taken into account, i.e. stress constraint, deformation constraint, vibration constraint, buckling constraint, and manufacturing maneuverability and continuity of laminate layups constraint. 


\section{- Stress constraint}

The tensile and compressive stresses generated by the loads cannot exceed associated allowable stresses. This can be expressed in the following inequality forms:

$$
\begin{aligned}
\sigma_{T, \max } & \leq \sigma_{T, \text { allow }} \\
\sigma_{C, \max } & \leq \sigma_{C, \text { allow }}
\end{aligned}
$$

where $\sigma_{T, \max }$ is the maximum longitudinal tensile stress of the blade, $\sigma_{T, \text { allow }}$ is the allowable longitudinal tensile stress of the material, $\sigma_{C, \max }$ is the maximum longitudinal compressive stress of the blade, $\sigma_{C, \text { allow }}$ is the allowable longitudinal compressive stress of the material.

$\sigma_{T, \text { allow }}$ and $\sigma_{C, \text { allow }}$ in Eqs. (3) and (4) are respectively given by the following equations:

$$
\begin{aligned}
& \sigma_{T, \text { allow }}=\sigma_{T, \text { ulti }} / f_{s} \\
& \sigma_{C, \text { allow }}=\sigma_{C, \text { ulti }} / f_{s}
\end{aligned}
$$

where $\sigma_{T, u l t i}$ is the ultimate longitudinal tensile stress, $\sigma_{C, u l t i}$ is the ultimate longitudinal compressive stress, $f_{s}$ is the material safety factor.

According to GL (Germanischer Lloyd) design standard [32] and Refs. [33, 34], the material safety factor $f_{s}$ for wind turbine composite blades is 2.204. According to Ref. [27], the ultimate stresses $\sigma_{T, u l t i}$ and $\sigma_{C, u l t i}$ of the unidirectional E-glass fibre $\mathrm{C} 260$ are $709.9 \mathrm{MPa}$ and $343.2 \mathrm{MPa}$, respectively. Thus, the allowable stresses $\sigma_{T, \text { allow }}$ and $\sigma_{C, \text { allow }}$ are respectively $322.1 \mathrm{MPa}$ and $155.7 \mathrm{MPa}$, taking account of a material safety factor of 2.204 .

\section{- Deformation constraint}

In order to avoid the uncertainties introduced by large blade deformations, the maximum blade deformation $d_{\max }$ should not exceed the allowable deformation $d_{\text {allow }}$. This can be expressed in the following inequality form:

$$
d_{\max } \leq d_{\text {allow }}
$$

The allowable deformation $d_{\text {allow }}$ in this study is set to $0.7 \mathrm{~m}$, which is $20 \%$ of the length of upper sail. This small allowable deformation avoids the uncertainties introduced by large deformations.

\section{- Vibration constraint}


In order to avoid the occurrence of resonance, the natural frequency of the composite blade should be separated from the harmonic vibration associated with rotor rotation. This can be expressed in the following inequality form:

$$
f_{\text {blade }}-f_{\text {rotor }} \geq \Delta_{\text {allow }}
$$

where $f_{\text {blade }}$ is the first natural frequency of the blade, $f_{\text {rotor }}$ is the frequency of the rotor rotation, $\Delta_{\text {allow }}$ is the associated allowable tolerance.

The maximum rotor rotational speed of ELECTRA wind turbine is 50rpm, and the associated frequency $f_{\text {rotor }}$ is $0.833 \mathrm{~Hz} . \Delta_{\text {allow }}$ is assumed to be $10 \%$ of $f_{\text {rotor }}$, and thus the following inequality form is obtained:

$$
f_{\text {blade }} \geq 0.92 \mathrm{~Hz}
$$

\section{- Buckling constraint}

Due to buckling, composite materials under axial compression are generally weaker than those under axis tension. The load multiplier $L_{m}$, which is the ratio of the critical buckling load to the applied load on the blade, should be larger than the allowable load multiplier $L_{m_{-} \text {allow }}$. This can be expressed in the following inequality form:

$$
L_{m} \geq L_{m_{-} \text {allow }}
$$

In this study, an empirical value of 1.5 is chosen for the allowable load multiplier $L_{m_{-} \text {allow }}$.

\section{- Manufacturing maneuverability and the continuity of laminate layups}

Considering the manufacturing maneuverability and the continuity of the laminate layup, the following constraints are applied to the design variables:

$$
\begin{aligned}
& x_{i}^{L} \leq x_{i} \leq x_{i}^{U} \quad i=1,2, \cdots, 23 \\
& x_{j_{\text {arm }}-}-x_{j_{\text {arm }}+1} \geq 0 \quad j_{\text {arm }}=1,2,3,4 \\
& x_{j_{j_{\text {Sail }} p}-}-x_{j_{\text {Sailp }}+1} \geq 0 \quad j_{\text {SailUp }}=8,9,10,11 \\
& \quad x_{8}-x_{13} \geq 0 \\
& x_{j_{\text {Sailown }}}-x_{j_{\text {SailDown }}+1} \geq 0 \quad j_{\text {SailDown }}=13,14,15
\end{aligned}
$$

where $x^{L}$ is the lower bound of the design variables; $x^{U}$ is the upper bound of the design variables.

The lower and upper bounds of the design variables and the constraint conditions are presented in Table 6. 
Table 6. Lower and upper bounds of the design variables and the constraint conditions

\begin{tabular}{|c|c|c|c|}
\hline Design variable & Lower bound & Upper bound & Units \\
\hline ArmRoot $x_{1}$ & 1 & 80 & - \\
\hline ArmRootTran $x_{2}$ & 1 & 70 & - \\
\hline ArmAf1 $x_{3}$ & 1 & 60 & - \\
\hline $\operatorname{ArmAf} 2 x_{4}$ & 1 & 50 & - \\
\hline ArmAf3 $x_{5}$ & 1 & 40 & - \\
\hline ArmTipTran $x_{6}$ & 1 & 50 & - \\
\hline ArmTip $x_{7}$ & 1 & 60 & - \\
\hline SailRoot $x_{8}$ & 1 & 60 & - \\
\hline SailUpTran $x_{9}$ & 1 & 50 & - \\
\hline SailUpAf1 $x_{10}$ & 1 & 40 & - \\
\hline SailUpAf2 $x_{11}$ & 1 & 30 & - \\
\hline SailUpAf3 $x_{12}$ & 1 & 20 & - \\
\hline SailDownTran $x_{13}$ & 1 & 50 & - \\
\hline SailDownAf1 $x_{14}$ & 1 & 40 & - \\
\hline SailDownAf2 $x_{15}$ & 1 & 30 & - \\
\hline SailDownAf3 $x_{16}$ & 1 & 20 & - \\
\hline ArmWeb $x_{17}$ & 5 & 15 & $\mathrm{~mm}$ \\
\hline SailUpWeb $x_{18}$ & 5 & 15 & $\mathrm{~mm}$ \\
\hline SailDownWeb $x_{19}$ & 5 & 15 & $\mathrm{~mm}$ \\
\hline ArmSparLoc1 $x_{20}$ & 0.15 & 0.3 & - \\
\hline ArmSparLoc $2 x_{21}$ & 0.35 & 0.5 & - \\
\hline SailSparLoc $1 x_{22}$ & 0.15 & 0.3 & - \\
\hline SailSparLoc $2 x_{23}$ & 0.35 & 0.5 & - \\
\hline$\sigma_{T}$ & & 322.1 & $\mathrm{MPa}$ \\
\hline$\sigma_{C}$ & & 155.7 & $\mathrm{MPa}$ \\
\hline$d_{\max }$ & & 0.7 & $\mathrm{~m}$ \\
\hline$f_{\text {blade }}$ & 0.92 & & $\mathrm{~Hz}$ \\
\hline$L_{m}$ & 1.5 & & - \\
\hline
\end{tabular}




\subsection{Parameter settings of genetic algorithm}

GA presented in Section 4 is chosen as the optimisation algorithm, and the main parameter settings of GA are presented in Table 7.

Table 7. Main parameter settings of GA

\begin{tabular}{cc}
\hline Parameter name & Value \\
\hline Type of initial sampling & Constrained sampling \\
Number of initial samples $N_{I n i}$ & 230 \\
Number of samples per iteration $N_{\text {Perfter }}$ & 50 \\
Maximum allowable Pareto Percentage [\%] & 70 \\
Convergence stability percentage [\%] & 2 \\
Maximum number of iterations $N_{\text {Maxter }}$ & 30 \\
Mutation probability & 0.01 \\
Crossover probability & 0.82 \\
\hline
\end{tabular}

Each parameter in Table 7 is detailed below.

\section{- Type of initial sampling}

The initial sampling is generated using constrained sampling algorithm, which constrains the sampling using variable relationships defined in Eqs. (11) to (15).

\section{- Number of initial samples}

In this study, the number of initial samples $N_{I n i}$ is 230 , which is 10 times the number of design variables.

\section{- Number of samples per iteration}

In this study, an empirical value of 50 is chosen as the number of samples per iteration $N_{\text {Perlter }}$.

\section{- Maximum allowable Pareto percentage}

This parameter is a convergence criterion. Pareto percentage is defined as the ratio of the number of desired Pareto points to the number of samples per iteration. When this percentage reaches the maximum allowable Pareto percentage (70\% in this study), the optimisation is converged. 


\section{- Convergence stability percentage}

Convergence stability percentage, which represents the stability of the population based on its mean and standard deviation, is a convergence criterion. When this percentage ( $2 \%$ in this study) is reached, the optimisation is converged.

\section{- Maximum number of iterations}

The maximum number of iterations, which is the maximum possible number of iterations the algorithm executes, is a stop criterion. If this number (30 in this study) is reached without the optimisation having reached convergence, the iteration will stop. It also provides an idea of the absolute maximum number of evaluations $N_{\text {MaxEvar }}$, which is given by the following equation:

$$
N_{\text {MaxEval }}=N_{\text {Ini }}+N_{\text {Perlter }} *\left(N_{\text {Maxiter }}-1\right)
$$

where $N_{I n i}$ is the number of initial sampling, $N_{\text {PerIter }}$ is the number of samples per iteration, $N_{\text {MaxIter }}$ is the maximum number of iterations.

\section{- Mutation probability}

Mutation probability, which defines the probability of applying a mutation on a design configuration, must be between 0 and 1. A larger value indicates a more random algorithm. For instance, if the value is 1 , the algorithm becomes a pure random search. In this study, a typical value of 0.01 [35] is used for the probability of mutation.

\section{- Crossover probability}

Crossover probability, which defines the probability with which parent solutions are recombined to produce the offspring solutions, must be between 0 and 1 . A smaller value indicates a more stable population and a faster (but less accurate) solution. For instance, if the value is 0 , the parents are directly copied to the new population. In this study, a typical value of 0.82 [36] is used for the probability of crossover.

\subsection{Flowchart of the optimisation model}

Figure 15 presents the flowchart of the optimisation model, which combines the parametric FEA model (presented in Section 3) and the GA model (presented in Section 4). 


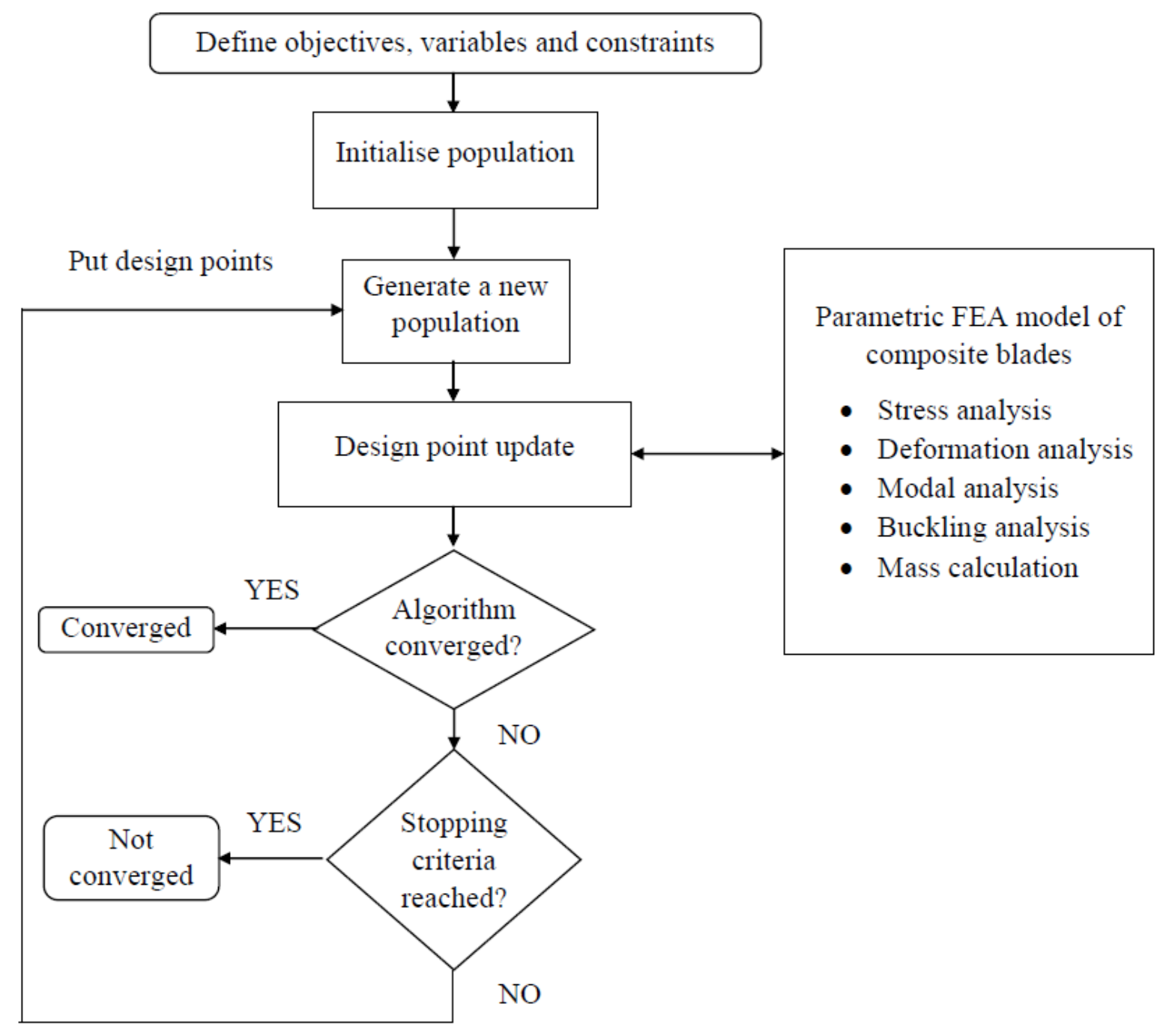

Figure 15. Flowchart of the optimisation model

\section{Results and discussions}

Figure 16 presents the history of the objective function (mass of the blade) during the optimisation process. As can be seen from Fig. 16, the mass of the blade oscillates in the first few iterative steps and then gradually converges, reaching the best result with a mass of $228 \mathrm{~kg}$ at the $28^{\text {th }}$ iteration. The optimal blade design leads to a mass reduction of $17.4 \%$ in comparison with the initial design (the initial blade mass at $0^{\text {th }}$ iteration is $276 \mathrm{~kg}$ ). 


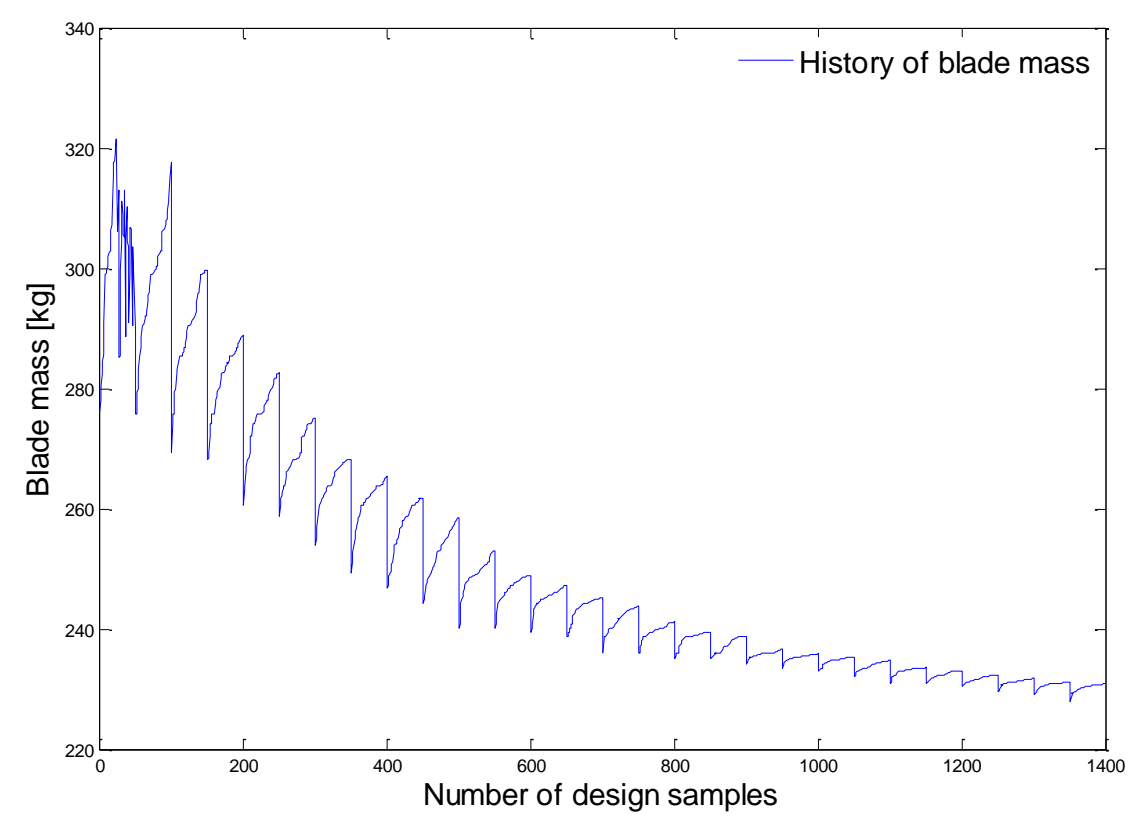

Figure 16. History of blade mass

Figs. 17 to 21 present the history of the maximum total deformation, maximum tensile stress, maximum compressive stress, first natural frequency of the blade and buckling load multiplier, respectively. The associated allowable values (i.e. upper/lower bounds) are also presented in these figures. As can be seen from Figs. 17 to 21, the maximum compressive stress is quite close to the allowable values, while other constraint parameters have relatively large margins from the allowable values. This indicates the compressive stress is the dominant parameter in the design in the present case. Choosing another composite material with higher compressive strength would further reduce the blade mass.

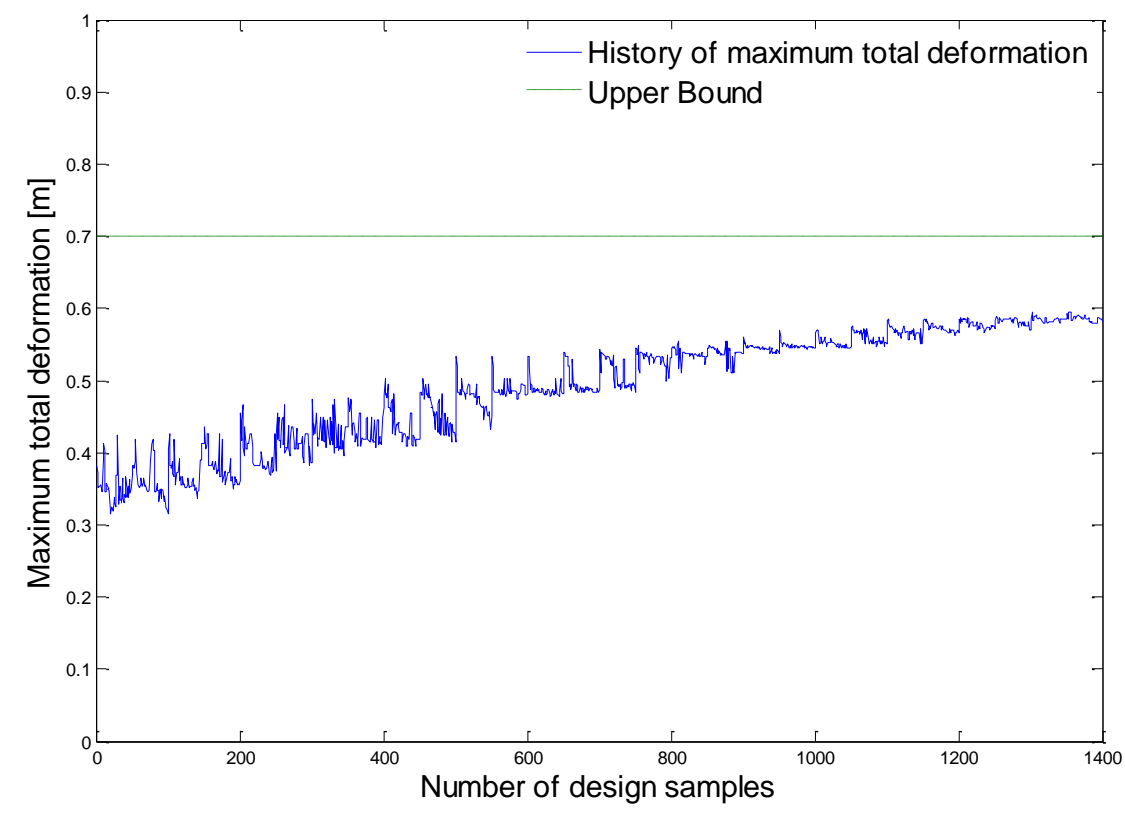

Figure 17. History of maximum total deformation 


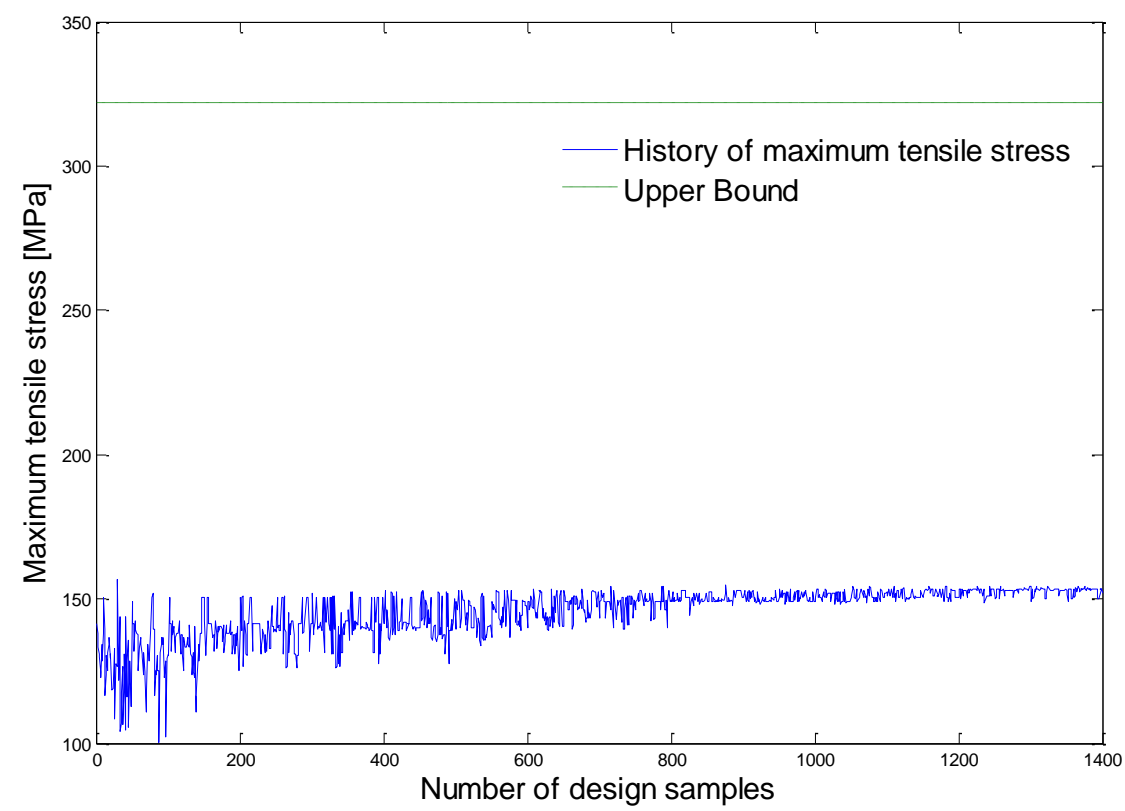

Figure 18. History of the maximum tensile stress

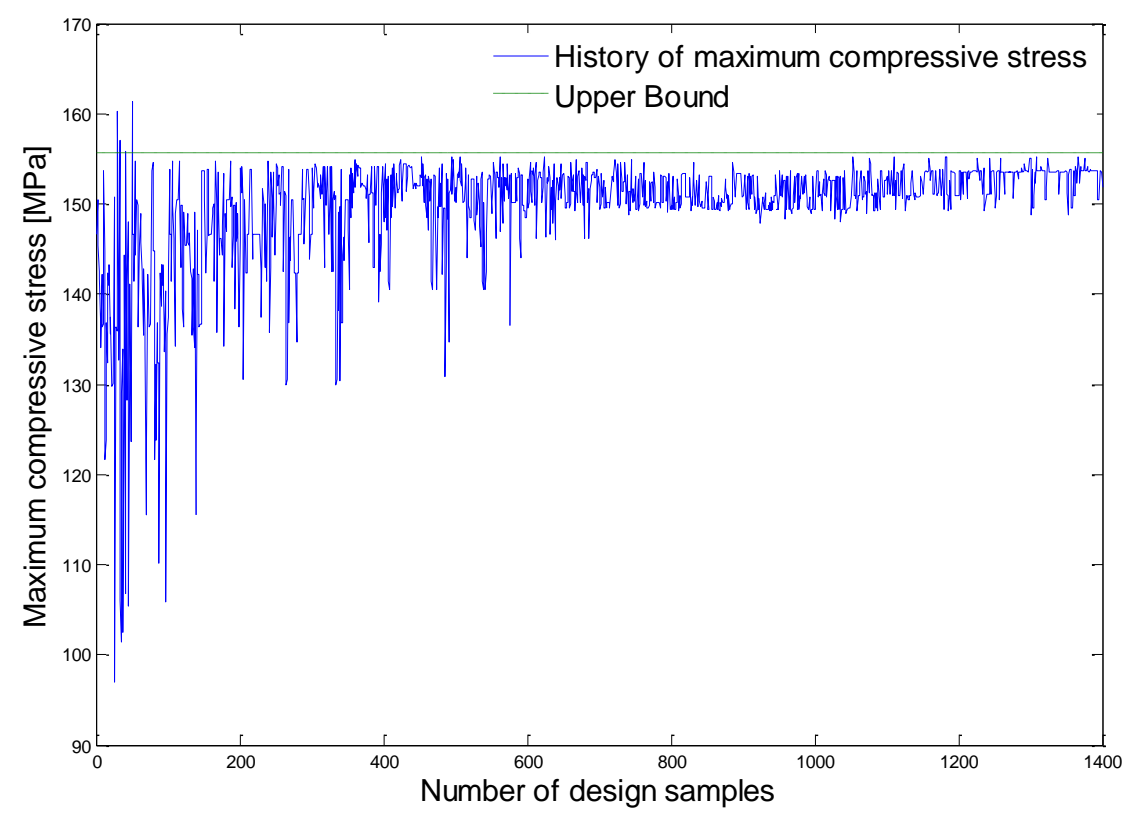

Figure 19. History of the maximum compressive stress 


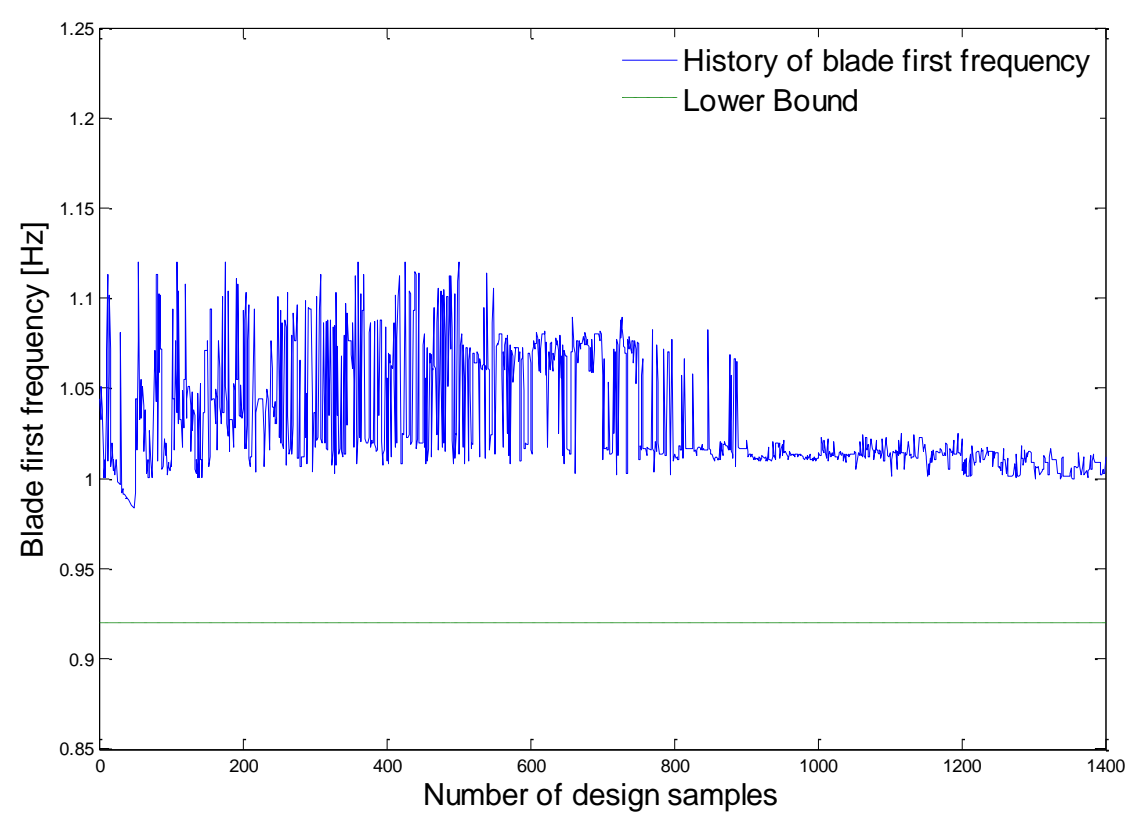

Figure 20. History of first natural frequency of the blade

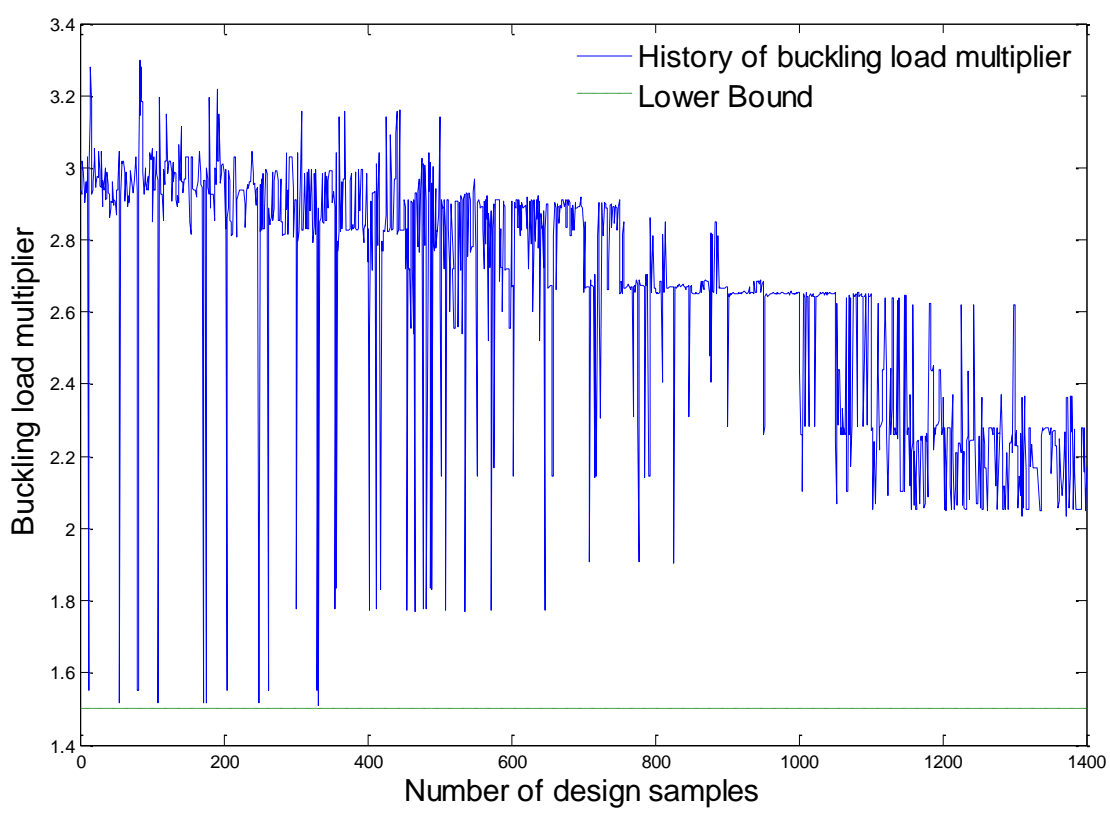

Figure 21. History of buckling load multiplier

The optimised results of design variables, which have been rounded up, are presented in Table 8 . As can be seen from Table 8, all design variables meet the constraints defined in Eqs. (11) to (15). 
Table 8. Optimised results of design variables

\begin{tabular}{|c|c|c|}
\hline Design variable & Optimal value & Unite \\
\hline$x_{1}$ & 40 & - \\
\hline$x_{2}$ & 22 & - \\
\hline$x_{3}$ & 21 & - \\
\hline$x_{4}$ & 13 & - \\
\hline$x_{5}$ & 3 & - \\
\hline$x_{6}$ & 19 & - \\
\hline$x_{7}$ & 25 & - \\
\hline$x_{8}$ & 33 & - \\
\hline$x_{9}$ & 21 & - \\
\hline$x_{10}$ & 17 & - \\
\hline$x_{11}$ & 8 & - \\
\hline$x_{12}$ & 6 & - \\
\hline$x_{13}$ & 20 & - \\
\hline$x_{14}$ & 16 & - \\
\hline$x_{15}$ & 10 & - \\
\hline$x_{16}$ & 5 & - \\
\hline$x_{17}$ & 8.8 & $\mathrm{~mm}$ \\
\hline$x_{18}$ & 8.5 & $\mathrm{~mm}$ \\
\hline$x_{19}$ & 7.5 & $\mathrm{~mm}$ \\
\hline$x_{20}$ & 0.203 & - \\
\hline$x_{21}$ & 0.388 & - \\
\hline$x_{22}$ & 0.229 & - \\
\hline$x_{23}$ & 0.387 & - \\
\hline
\end{tabular}

The blade stress distributions, deformations, first modal frequency, and buckling analysis results for the optimised blade are presented below.

\section{- Stress distributions}

Figure 22 presents the normal stress distributions within the blade structure. From Fig. 22 we can see that 1) the maximum positive normal stress (i.e. maximum tensile stress) is $151.72 \mathrm{MPa}$, which is $52.90 \%$ lower 
than the allowable value of $322.1 \mathrm{MPa}$; and 2) the absolute value of maximum negative normal stress (i.e. maximum compressive stress) is $151.28 \mathrm{MPa}$, which is quite close to the allowable value of $155.7 \mathrm{MPa}$.

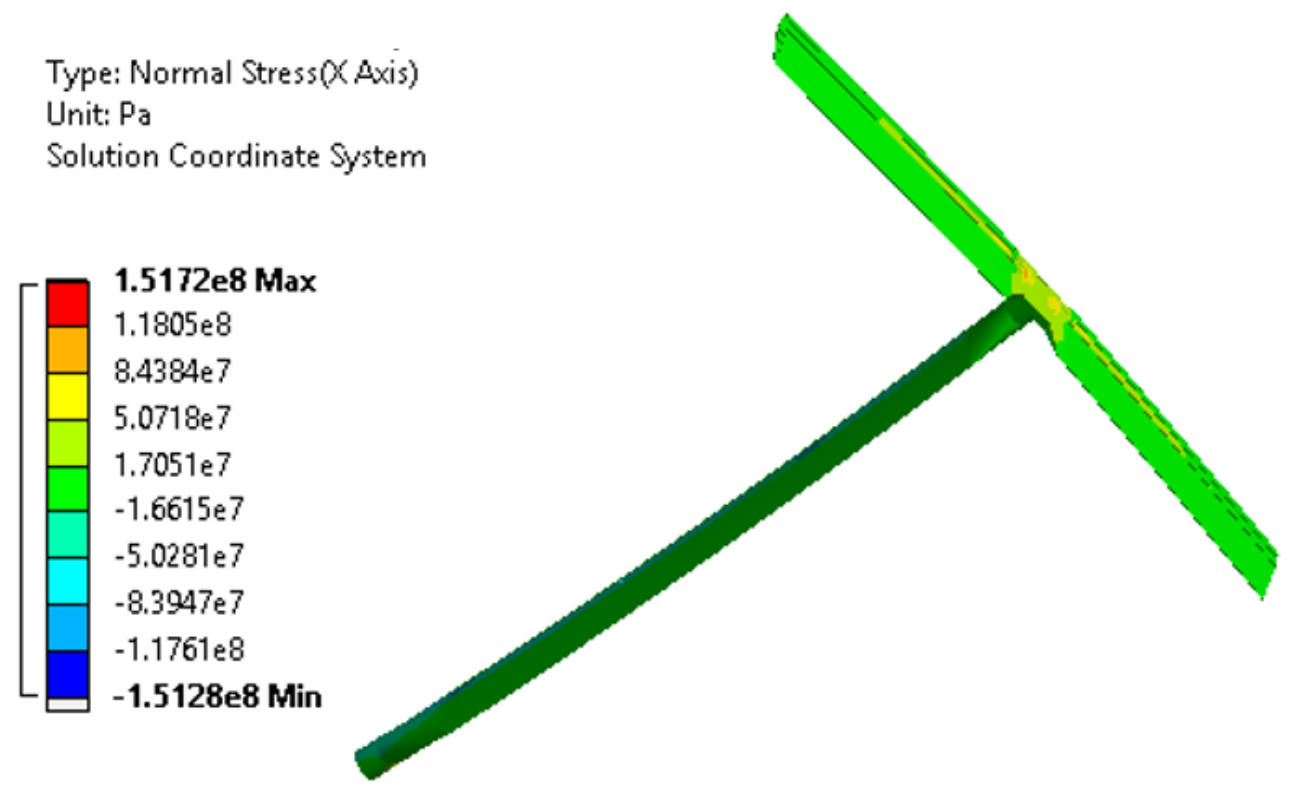

Figure 22. Normal stress distributions of the blade structure

\section{- Blade deformations}

Figure 23 presents the total deformations of the blade. The un-deformed wireframe is also presented in this figure to facilitate the illustration. As can be seen from Fig. 23, the maximum total deformation is about $0.593 \mathrm{~m}$, observed at the tip of the upper sail. This value is $15.3 \%$ lower than the allowable value of $0.7 \mathrm{~m}$, indicating the present blade design is quite stiff and is not likely to experience large deformations.

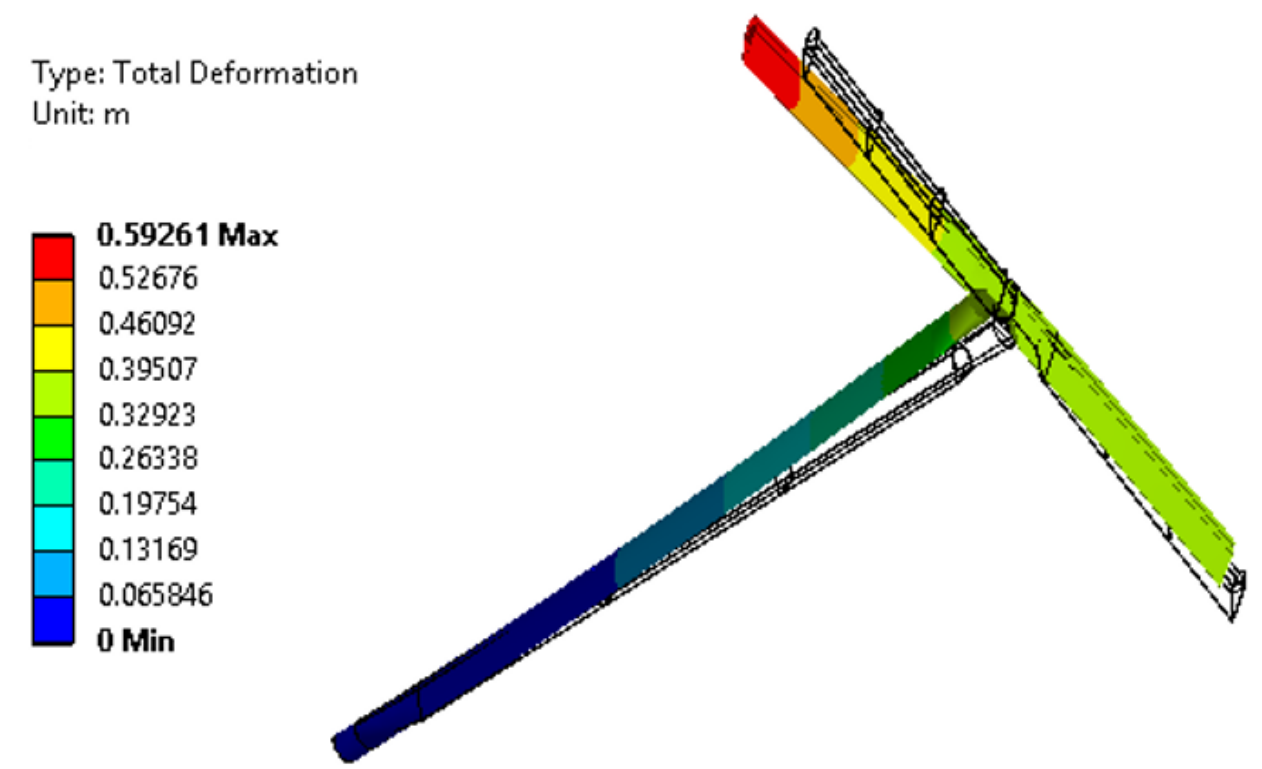

Figure 23. Total deformations of the blade structure 


\section{- Modal frequencies and shapes}

The modal analysis is used to obtain the dynamic properties of the blade, such as modal frequencies and modal shapes. In this case, the blade is non-rotating and free-vibration (no loads on the blade). Fig. 24 presents the frequency and modal shape of the first mode of the blade. As can be seen from Fig. 24, the mode frequency is about $1.0 \mathrm{~Hz}$, which is $8.7 \%$ higher than the allowable value of $0.92 \mathrm{~Hz}$.

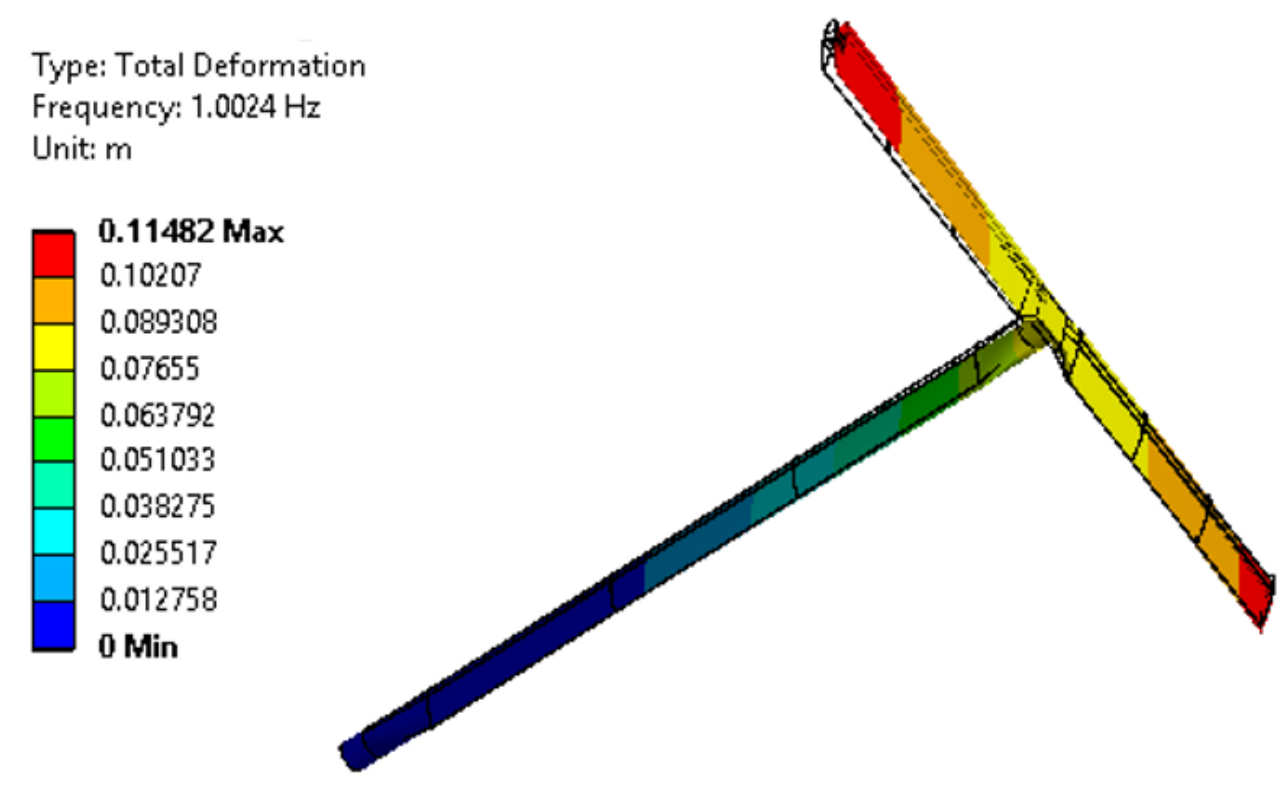

Figure 24. Modal frequency and modal shape of first mode of the blade

\section{- Buckling analysis results}

Due to buckling, composite materials under axial compression are generally weaker than those under axis tension. Fig. 25 presents the buckling analysis results of the blade. As can be seen from Fig. 25, the load multiplier is about 2.15 , which is $43.33 \%$ higher than the allowable value of 1.5 . This indicates the present blade design is not likely to suffer from buckling failure. 
Type: Total Deformation

Load Multiplier: 2.1536

Unit: $m$
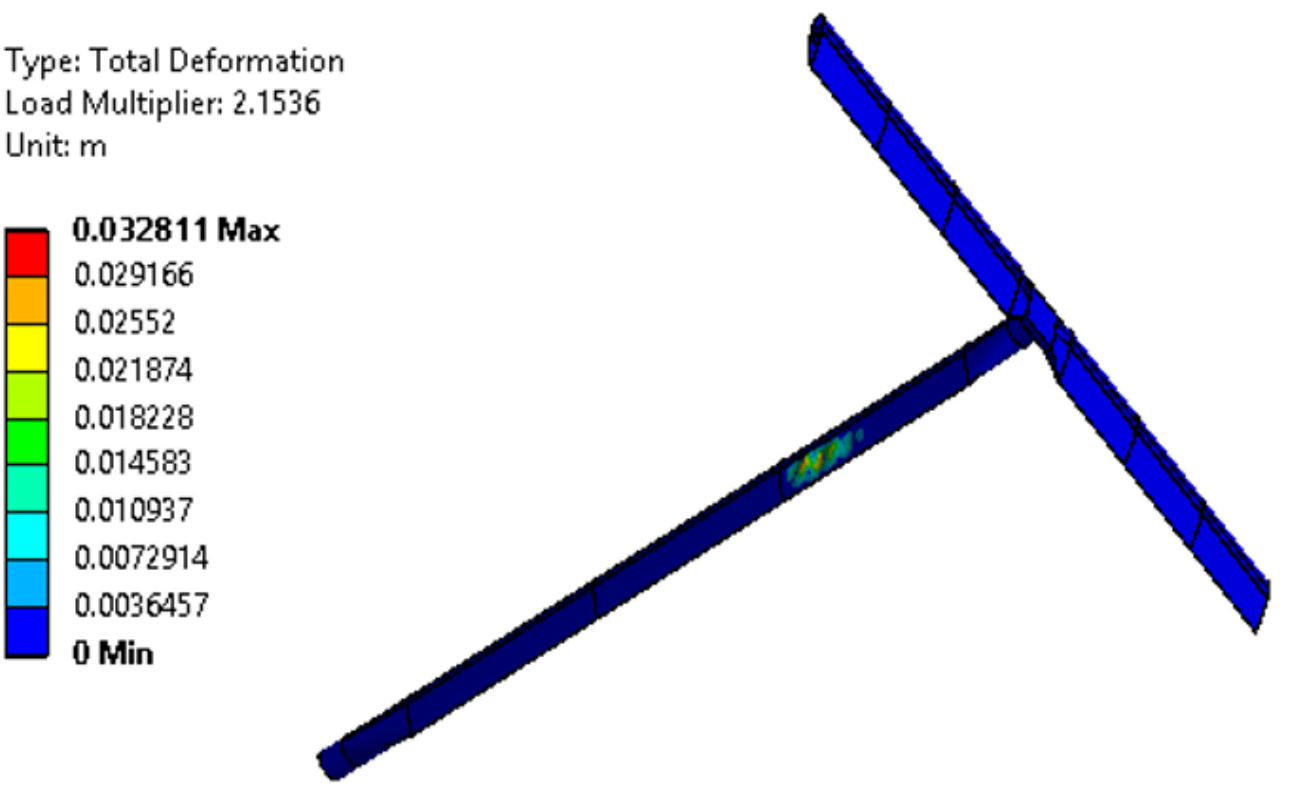

Figure 25. Buckling load multiplier and buckling mode shape of the blade

\section{Conclusions}

In this work, a structural optimisation model for wind turbine composite blades has been developed by combining 1) a parametric FEA (finite element analysis) model, which provides a high-fidelity solution of the global behaviour of the blade; with 2) a GA (generic algorithm) model, which handles the design variables and searches for the optimal solutions. The structural optimisation model minimises the mass of the blade with multi-criteria constraint conditions. The number of unidirectional plies, the location of the spar cap and the thickness of shear webs are taken as the design variables. The optimisation model takes account of five constraint conditions, i.e. stress constraint, deformation constraint, vibration constraint, buckling constraint, and manufacturing maneuverability and continuity of laminate layups constraint. The model was applied to the blade structural optimisation of ELECTRA 30kW wind turbine, which is a novel vertical-axis wind turbine combining sails and V-shape arm. The following conclusions can be drawn from the present study:

- Good agreement (with maximum percentage difference of 2.63\%) is achieved in comparison with the modal analysis results of WindPACT $1.5 \mathrm{MW}$ wind turbine composite blade reported in the literature, confirming the validity of the parametric FEA model developed in the present study.

- The structural optimisation model developed in this paper is capable of effectively and accurately determining the optimal structural layups of composite blades, significantly improving the efficiency of blade structural optimisation.

- The mass of the optimised blade is $228 \mathrm{~kg}$, which is $17.4 \%$ lower than the initial design, indicating the blade mass can be significantly reduced by using the present optimisation model. 
- For the optimal blade, the maximum compressive stress is quite close to the allowable values, while other constraint parameters (i.e. maximum total deformation, maximum tensile stress, first natural frequency of the blade and buckling load multiplier) have relatively large margins from the allowable values. This indicates the compressive stress is the dominant parameter in the presented design case. Choosing another composite material with higher compressive strength would further reduce the blade mass.

- The present model can be used for any practice of structural optimisation of wind turbine composite blades, minimising the blade mass with multi-criterion constraint conditions.

\section{Acknowledgements}

Authors gratefully acknowledge the financial support of UK Government's Department of Energy \& Climate Change and Aerogenerator Project Limited, who is the IP holder of the ELECTRA vertical axis wind turbine configuration concept.

\section{References}

[1] A. Kolios, A. Chahardehi, and F. Brennan, "Experimental determination of the overturning moment and net lateral force generated by a novel vertical axis wind turbine: experiment design under load uncertainty," Experimental Techniques, vol. 37, pp. 7-14, 2013.

[2] L. Wang, A. Kolios, P.-L. Delafin, T. Nishino, and T. Bird, "Fluid Structure Interaction Modelling of A Novel 10MW Vertical-Axis Wind Turbine Rotor Based on Computational Fluid Dynamics and Finite Element Analysis," presented at the EWEA 2015 Annual Event, Paris, France, 2015.

[3] M. Borg, M. Collu, and A. Kolios, "Offshore floating vertical axis wind turbines, dynamics modelling state of the art. Part II: Mooring line and structural dynamics," Renewable and Sustainable Energy Reviews, vol. 39, pp. 1226-1234, 2014.

[4] M. H. Worstell, "Aerodynamic performance of the DOE/Sandia 17-m-diameter vertical-axis wind turbine," Journal of Energy, vol. 5, pp. 39-42, 1981.

[5] D. J. Sharpe, "Vertical axis turbine apparatus," ed: Google Patents, 2011.

[6] J. Chatterton, D. Parsons, J. Nicholls, P. Longhurst, M. Bernon, A. Palmer, et al., "Carbon brainprintAn estimate of the intellectual contribution of research institutions to reducing greenhouse gas emissions," Process Safety and Environmental Protection, vol. 96, pp. 74-81, 2015.

[7] D. J. Parsons, J. C. Chatterton, F. P. Brennan, and A. J. Kolios, "Carbon Brainprint Case Study: novel offshore vertical axis wind turbines," Cranfield University, 2011.

[8] X. Liu, L. Wang, and X. Tang, "Optimized linearization of chord and twist angle profiles for fixedpitch fixed-speed wind turbine blades," Renewable Energy, vol. 57, pp. 111-119, 2013.

[9] L. Wang, X. Tang, and X. Liu, "Blade design optimisation for fixed-pitch fixed-speed wind turbines," ISRN Renewable Energy, vol. 2012, 2012.

[10] L. Wang and X. Liu, "Optimized chord and twist angle distributions of wind turbine blade considering Reynolds number effects," in Wind Energy: Materials, Engineering and Policies (WEMEP), 2012.

[11] G. S. Bir and P. G. Migliore, Preliminary structural design of composite blades for two-and three-blade rotors: Citeseer, 2004.

[12] L. Wang, "Nonlinear aeroelastic modelling of large wind turbine composite blades," University of Central Lancashire, 2015.

[13] L. Wang, X. Liu, N. Renevier, M. Stables, and G. M. Hall, "Nonlinear aeroelastic modelling for wind turbine blades based on blade element momentum theory and geometrically exact beam theory," Energy, vol. 76, pp. 487-501, 2014. 
[14] L. Wang, X. Liu, L. Guo, N. Renevier, and M. Stables, "A mathematical model for calculating crosssectional properties of modern wind turbine composite blades," Renewable Energy, vol. 64, pp. 52-60, 2014.

[15] J. N. Reddy, Mechanics of laminated composite plates and shells: theory and analysis: CRC press, 2004.

[16] M. Shama, Torsion and shear stresses in ships: Springer Science \& Business Media, 2010.

[17] J. F. Herbert-Acero, O. Probst, P.-E. Réthoré, G. C. Larsen, and K. K. Castillo-Villar, "A Review of Methodological Approaches for the Design and Optimization of Wind Farms," Energies, vol. 7, pp. 6930-7016, 2014.

[18] H. Xuan, Z. Weimin, L. Xiao, and L. Jieping, "Aerodynamic and aeroacoustic optimization of wind turbine blade by a genetic algorithm," in Proceedings of 46th AIAA Aerospace Sciences Meeting and Exhibit, 2008, pp. 2008-1331.

[19] K. Yassin, A. Diab, and Z. Ghoneim, "Aerodynamic Optimization of a Wind Turbine Blade Designed for Egypt's Saharan Environment Using a Genetic Algorithm," Renewable Energy and Sustainable Development, vol. 1, pp. 106-112, 2015.

[20] ANSYS, "Version 15.0; ANSYS," Inc.: Canonsburg, PA, USA November, 2013.

[21] ANSYS, "ANSYS help documentation," Inc.: Canonsburg, PA, USA November, 2013.

[22] D. Malcolm and A. Hansen, "WindPACT turbine rotor design study," National Renewable Energy Laboratory, Golden, CO, vol. 5, 2002.

[23] D. A. Griffin, "WindPACT Turbine design scaling studies technical area 1œComposite blades for 80-to 120-meter rotor," National Renewable Energy Laboratory Technical report, 2001.

[24] B. Resor and T. Bushnell, "A 1.5 MW NuMAD Blade Model," Draft Report, Sandia National Laboratories, Albuquerque, NM, 2011.

[25] http://www.nrel.gov/wind/windpact.html; accessed 28-July-2014.

[26] D. Berry and T. Ashwill, "Design of 9-meter carbon-fiberglass prototype blades: CX-100 and TX-100," SAND2007-0201, Sandia National Laboratories, Albuquerque, NM, 2007.

[27] J. W. Lee, S. N. Gangadharan, and M. Mirmirani, "A Baseline Study and Calibration for Multidisciplinary Design Optimization of Hybrid Composite Wind Turbine Blade," in 52nd AIAA/ASME/ASCE/AHS/ASC Structures, Structural Dynamics and Materials Conference 19th AIAA/ASME/AHS Adaptive Structures Conference 13t, 2011, p. 1902.

[28] A. Shires, "Development and evaluation of an aerodynamic model for a novel vertical axis wind turbine concept," Energies, vol. 6, pp. 2501-2520, 2013.

[29] I. Paraschivoiu, "Double-multiple streamtube model for studying vertical-axis wind turbines," Journal of propulsion and power, vol. 4, pp. 370-377, 1988.

[30] I. Commission, "IEC 61400-2: Wind Turbines-Part 2: Design requirements for small wind turbines," ed: IEC, 2006.

[31] S. Sivanandam and S. Deepa, Introduction to genetic algorithms: Springer Science \& Business Media, 2007.

[32] G. W. Guideline and G. Lloyd, "Guideline for the certification of Wind Turbines," Hamburg: Germanischer Lloyd Wind Energie Gmb H, 2010.

[33] C. Bak, F. Zahle, R. Bitsche, T. Kim, A. Yde, L. Henriksen, et al., "The DTU 10-MW reference wind turbine," Danish wind power research, 2013.

[34] D. T. Griffith and T. D. Ashwill, "The Sandia 100-meter all-glass baseline wind turbine blade: SNL10000," Sandia National Laboratories, Albuquerque, Report No. SAND2011-3779, 2011.

[35] R. E. Perez, J. Chung, and K. Behdinan, "Aircraft conceptual design using genetic algorithms," AIAA Paper, vol. 4938, 2000.

[36] M. Gandomkar, M. Vakilian, and M. Ehsan, "A combination of genetic algorithm and simulated annealing for optimal DG allocation in distribution networks," CCECE/CCGEI, Saskatoon, pp. 645648, 2005. 